\title{
O "Princípio de Pascal" nos livros do PNLD 2018: uma análise crítica multicontextual (histórica e conceitual)
}

"Pascal's Principle" in PNLD 2018 textbooks: a multicontextual critical analysis (historical and conceptual)

\author{
Juliana M. Hidalgo ${ }^{* 1,2 @}$, Daniel de Medeiros Queiroz $^{2}$, Dory H.A.L. Anselmo ${ }^{1,3}$
}

\author{
${ }^{1}$ Universidade Federal do Rio Grande do Norte, Departamento de Física, Natal, RN, Brasil. \\ ${ }^{2}$ Universidade Federal do Rio Grande do Norte, Programa de Pós-Graduação em Ensino de Ciências Naturais e \\ Matemática, Natal, RN, Brasil \\ ${ }^{3}$ Universidade do Estado do Rio Grande do Norte, Programa de Pós-Graduação em Física, Mossoró, RN, Brasil.
}

Recebido em 19 de fevereiro de 2021. Revisado em 21 de junho de 2021. Aceito em 24 de junho de 2021.

\begin{abstract}
Esse trabalho apresenta uma avaliação crítica multicontextual, histórica e conceitual, do Princípio de Pascal nos livros didáticos de Física aprovados no Programa Nacional do Livro Didático (PNLD) 2018. A análise realizada levou em consideração os seguintes aspectos: o enunciado do Princípio de Pascal sob o ponto de vista conceitual; relações entre ciência e tecnologia, tendo em vista dispositivos relacionados ao Princípio; fontes históricas primárias e secundárias relacionadas ao desenvolvimento do Princípio de Pascal; fundamentação historiográfica e apontamentos da legislação educacional para a inserção didática da História e da Filosofia da Ciência. Foram notadas inconsistências no que diz respeito à aplicabilidade do Princípio de Pascal, visões simplistas sobre a ciência e sobre as relações entre ciência e tecnologia, distorções históricas, anacronismos e abordagens historicamente descontextualizadas. Em face do referido cenário, são apontadas sugestões para uma inserção didática mais adequada.
\end{abstract}

Palavras-chave: Livros didáticos, PNLD 2018, Princípio de Pascal.

This paper presents a multicontextual, historical and conceptual, critical analysis of Pascal's Principle in Brazilian Physics textbooks from Programa Nacional do Livro Didático (PNLD) 2018. The analysis considered the following aspects: the statement of Pascal's Principle from a conceptual perspective; relations between science and technology, in view of devices associated to the Principle; primary and secondary historical sources related to the development of Pascal's Principle; historiographical foundation; and notes from Brazilian educational legislation concerned to didactic insertion of History and Philosophy of Science. We noticed inconsistencies regarding the applicability of Pascal's Principle, simplistic views on science and on the relationship between science and technology, historical distortions, anachronisms, and historically decontextualized approaches. Suggestions are made considering this scenario, aiming at a more adequate didactic insertion.

Keywords: Textbooks, PNLD 2018, Pascal's Principle.

\section{Introdução}

No ano 2000, os Parâmetros Curriculares Nacionais para o Ensino Médio apontavam a necessidade de que o conhecimento físico fosse "explicitado como um processo histórico" [1, p. 24]. Ao longo das últimas décadas, a legislação educacional brasileira tem apresentado considerações relacionadas à História e Filosofia da Ciência. Mais recentemente, a versão em vigor da Base Nacional Comum Curricular recomenda em relação à contextualização histórica "a comparação de distintas explicações científicas propostas em diferentes épocas e culturas e o reconhecimento dos limites explicativos das ciências, criando oportunidades para que os estudantes compreendam a dinâmica da construção do conhecimento científico" [2, p. 550].

\footnotetext{
*Endereço de correspondência: julianahidalgo@fisica.ufrn.br
}

A legislação educacional separa, bem como o fazem os editais do Programa Nacional do Livro Didático, o joio do trigo. A atual Base Nacional Comum Curricular ${ }^{1}$ explicita que não são adequados "modelos" de História da Ciência restritos a nomes famosos, datas e informações biográficas descontextualizadas ${ }^{2}$ "a contextualização histórica não se ocupa apenas da menção a nomes de cientistas e a datas da história da Ciência, mas de apresentar os conhecimentos científicos como construções socialmente produzidas, com seus impasses

\footnotetext{
${ }^{1}$ Houve três versões da Base Nacional Comum Curricular, sendo o processo de elaboração desse documento marcado por disputas em relação ao papel da $\mathrm{HFC}$.

2 Esses modelos, ainda presentes na Educação Científica, vêm sendo sujeitos a críticas, tais como as deferidas por Nardi e Silva: "Narrativas clássicas sobre a história da ciência costumam concentrar-se nos feitos de pessoas mais famosas, contribuindo para aumentar suas famas e tornando ainda menos conhecidas as contribuições de pesquisadores que por várias razões não entraram no seleto grupo de celebridades históricas" [3, p. e20200396-1].
} 
e contradições" [2, p. 550]. Em explícita rejeição a uma visão socialmente neutra da ciência, o mesmo documento legal aponta que a "contextualização social, histórica e cultural da ciência e da tecnologia é fundamental para que elas sejam compreendidas como empreendimentos humanos e sociais" [2, p. 549]. Discurso semelhante pode-se observar no mais recente edital do Programa Nacional do Livro Didático para o Ensino Médio (PNLD 2018), segundo o qual se deve explorar "o contexto social, cultural, econômico e político em que ocorreu a produção científica" [4, p. 46]. Especificamente para a Física, o edital reforça que "todas as construções do conhecimento físico são fortemente permeadas pelos contextos sócio-políticocultural-histórico-econômicos em que se desenvolvem" [4, p. 54].

A literatura acadêmica especializada advoga a favor da História da Ciência no contexto do ensino de disciplinas científica:3

\begin{abstract}
A história da ciência (HC) pode ser utilizada como um excelente recurso pedagógico para ensinar disciplinas de cunho científico, pois com ela é possível tornar as aulas mais desafiadoras e reflexivas, ao passo que ela permite que o aluno compreenda melhor o significado dos conceitos trabalhados em sala de aula [6, p. e20190114-5].
\end{abstract}

Trata-se de uma perspectiva não meramente ilustrativa ou como introdução acessória aos conteúdos [7, 8]. Estabelece-se a inadequação de uma história meramente cronológica. Rejeita-se o modelo reduzido à apologia a virtudes heroicas, grandes descobertas $\mathfrak{4}^{4}$ e realizações dos pesquisadores (história hagiográfica, Whit 5 ] e à história de "pais" da ciência (história Pedigree), as quais

\footnotetext{
3 Tal afirmação geral, contudo, não significa perder de vista que: "O reconhecimento das diferentes ênfases curriculares para o ensino de ciências permite uma avaliação ampla do papel da história das ciências. Ele dependerá muito da perspectiva adotada em determinado momento e do tópico a ser trabalhado. [...] podese afirmar que praticamente qualquer assunto em uma ênfase filosófico-cultural será bem desenvolvido por episódios históricos; por outro lado, poucas questões do cotidiano exigem este tratamento. Assim, a história das ciências pode ter papel de destaque na aprendizagem de estudantes ou pode simplesmente não ter relevância nas mesmas" 5. pp. 335-336].

4 Bagdonas, Zanetic e Gurgel destacam que: "na historiografia contemporânea, não há mais o interesse de debater prioridades científicas como forma de buscar quem deveria receber, por justiça, o crédito merecido. Os historiadores da ciência são atualmente céticos sobre o conceito de 'descoberta' como um evento discreto para o qual certa pessoa deve receber 'crédito' ou 'prioridade'. [...] Kuhn defendeu que o modo como normalmente se usa o termo 'descoberta' induz a erros sobre como ocorre o processo de criação de teorias científicas. Quando se diz que alguém descobriu algo em certa data temos a impressão de um acontecimento pontual e individual, mas isso raramente acontece na história da ciência." 9] p. e2602-11].

5 A história Whig "exalta o individualismo na figura de seres especiais, diferenciados, com contribuições relevantes à ciência. [...] despreza o envolvimento de um sem número de estudiosos que, direta ou indiretamente, em maior ou menor medida, contribuem para o progresso da ciência" [10, pp. 36-37].
}

podem colaborar, por exemplo, para a disseminação de visões individualistas e simplista: ${ }^{6}$ sobre a ciência [12. Há indicativos sobre cuidados na inserção didática da História da Ciência:

[...] faz-se uma seleção que simplifica em parte os fatos históricos [...], mas cuidando para que as omissões não conduzam a uma pseudo-história [...] e evitem, assim, uma imagem distorcida da ciência [...]. Igualmente, deve-se evitar mostrar uma visão mítica dos cientistas e da ciência [...], que enfatiza alguns aspectos, minimiza outros ou omite erros e fracassos [...]. Também não se deve promover uma interpretação anacrônica do passado [...]. [13, pp. 141-142]

Historiadores, em especial, alertam que visões excessivamente simplificadas de episódios históricos podem cumprir o efeito contrário em relação ao esperado na formação de estudantes. Narrativas anedóticas e/ou anacrônicas podem carregar de imprecisões conceituais a visões estereotipadas da atividade científica. Em 1974, Steven Brush já alertava para a importância de professores terem o cuidado de apresentar os episódios a partir de interpretações atualizadas da história das ciências. Se isso era válido há quase 50 anos, o conselho ganha mais importância quando se constata que a historiografia se renovou muito nos últimos anos [...]. [5. p. 336]

A História da Ciência a ser inserida no contexto educacional vem alinhada a preceitos historiográficos atuais [14], colaborando para a propagação de visões mais sofisticadas a respeito da ciência. Explora diacronicamente contextos, situando a ciência como construção humana coletiva $\sqrt{7}$

De acordo, portanto, com as perspectivas da legislação educacional e da literatura acadêmica especializada, propostas pedagógicas não devem ser exclusivamente focalizadas nos produtos da ciência. Contudo, ainda que não faltem alertas, nota-se que os conteúdos científicos costumam ser apresentados nos livros didáticos de forma descontextualizada, sem referência ao seu desenvolvimento histórico.

Os livros científicos didáticos enfatizam os resultados aos quais a ciência chegou - as teorias e conceitos que aceitamos, as técnicas

\footnotetext{
${ }^{6}$ Para uma definição de visões simplistas sobre a ciência, incluindo a individualista, ver 11 .

7 É importante pontuar, contudo, que essa afirmação não implica a alegação de que abordagens histórico-filosóficas sejam as únicas possíveis para a problematização de visões simplistas sobre a ciência. Visões ingênuas sobre a ciência e a tecnologia, por exemplo, podem ser problematizadas a partir de outros pontos de vista, sendo uma das preocupações centrais da perspectiva CTSA.
} 
de análise que utilizamos - mas não costumam apresentar algum outro aspecto da ciência. De que modo as teorias e os conceitos se desenvolvem? Como os cientistas trabalham? Quais as ideias que não aceitamos hoje em dia e que eram aceitas no passado? [7. p. xvii].

Há simplificações grosseiras na alusão a elementos históricos em livros didáticos e omissões com consequências perniciosas [15 17]. Para percebê-las, isto é, para uma apreciação crítica de determinado conteúdo científico nos livros didáticos sob o viés histórico-filosófico, é preciso levar em conta, por exemplo, elementos de cunho historiográfico e visões de ciência, bem como certo conhecimento a respeito do desenvolvimento histórico do conteúdo científico em questão.

Balizados pelos referidos elementos, além de considerações decorrentes do ponto de vista físico-conceitual e a respeito das relações entre ciência e tecnologia, analisamos todos os 12 (doze) exemplares de livros didáticos de Física para o Ensino Médio aprovados no PNLD 2018 [18-29], enfocando o conteúdo relacionado ao Princípio de Pascal. ${ }^{8}$ As seções subsequentes do presente trabalho trazem: as questões norteadoras da análise realizada; a análise do conteúdo físico específico nos livros didáticos, o que inclui referências a aspectos do desenvolvimento histórico do Princípio de Pascal e considerações analíticas que demonstram a validade física atual do Princípio; sugestões para uma inserção didática multicontextual do Princípio de Pasca $9^{9}$ e considerações finais.

Por que é relevante entendermos como o Princípio de Pascal se apresenta nos livros didáticos no tocante aos elementos supracitados? Por que uma abordagem histórico-filosófica desse conteúdo é pertinente?

Justificamos que seria importante tratar o Princípio de Pascal de forma contextualizada historicamente. Há no ensino do conceito de pressão uma peculiaridade que não deveria ser ignorada. Os estudantes da Educação Básica, não raro, costumam se confundir quanto ao caráter da grandeza pressão, tomando-a como vetorial, em lugar

\footnotetext{
8 Realizamos também uma análise do Princípio de Pascal em livros didáticos em inglês, para o Ensino Superior, utilizados na formação de físicos (bacharéis ou licenciados), engenheiros etc. Os resultados dessa análise foram recentemente publicados em periódico internacional 30. Mais adiante, discutimos como os resultados encontrados nos livros didáticos para o ensino superior se relacionam aos que serão apresentados no presente artigo.

9 É no sentido exposto nos trechos da BNCC, transcritos nessa seção introdutória do presente trabalho, que entendemos a expressão "contextualização histórica". De acordo com os referidos trechos, uma abordagem contextualizada deve contemplar elementos que permitam apresentar os conhecimentos científicos como construções socialmente produzidas, oportunizando ao estudante a percepção da dinâmica da construção do conhecimento científico, por exemplo, por meio da comparação de explicações científicas distintas propostas em diferentes épocas [2, p. 550]. Dessa forma, explicitamos como contextualizada a proposta apresentada no final desse artigo.
}

de escalar. Pressão e força se confundem. A abordagem histórico-filosófica pode contribuir para que esse aspecto seja esclarecido de forma muito oportuna, por meio do contraste entre a redação dada por Pascal ao enunciado do Princípio e a sua redação atual. Essa perspectiva permite também que o aluno perceba a história do conceito físico, de forma a notar que esse não foi prontamente definido em sua forma hodierna. Trabalhar o Princípio de Pascal a partir de uma perspectiva histórica avigora a percepção da Física como construção social humana, bem como possibilita que sejam discutidas relações entre ciência e tecnologia de forma contextualizada.

\section{Questões Norteadoras da Análise}

Realizamos uma abordagem multicontextual 10 física e histórico-filosófica, sobre a forma como o Princípio de Pascal aparece nos livros do PNLD 2018. Recorremos a fontes históricas primárias e secundárias, relacionadas ao Princípio de Pascal, como recurso para a análise de eventuais alusões de cunho histórico-filosófico nos livros didáticos 11

A análise exibida na seção subsequente foi dividida em tópicos: "Autoria do Princípio", "Apresentação do conceito de pressão", "Aplicações' do Princípio - relações entre ciência e tecnologia" e "Aplicabilidade do Princípio"

Para os três primeiros tópicos, a apresentação dos resultados é precedida por menções a elementos históricofilosóficos tomados como recorte. Em busca desses elementos relacionados ao processo de construção dos conceitos científicos, consideramos que:

A História revive os elementos do pensar da época, revelando, pois, os ingredientes com que o pensamento poderia ter contado na época em que determinada conquista foi feita. Ela desvenda a lógica da construção conceitual; nesse esforço, ela revela, também, os "buracos lógicos" que o conceito preenche, revivendo o próprio ato intelectual da criação científica [38, p. 227].

Alguns questionamentos serão pertinentes em razão de elementos que emergem do estudo das fontes históricas:

\footnotetext{
10 Esclarecemos que a expressão "abordagem multicontextual" é aqui utilizada em sentido limitado, em estrita referência aos vieses histórico-filosófico e conceitual. Não há a intenção aqui de abranger perspectivas mais amplas, por exemplo, relacionadas a política, economia, artes etc.

11 Ao recorrermos a essas fontes [31-36 não estamos apontando que existe a História da Ciência verdadeira a ser inserida no contexto educacional. Seria uma ingenuidade tal depreensão. Ao contrário, "há muitas (e boas) histórias da física, que diferem entre si tanto pela escolha e pelo grau de aprofundamento dos conteúdos abordados como pelos interesses, conhecimentos e concepções epistemológicas de seus autores" [37 p. 16]. Em busca de uma possível História da Ciência adequada, porque bem fundamentada, recorremos às referidas fontes.
} 
a matematização, a redação atual do Princípio e o entendimento da sua aplicabilidade, por exemplo, a fluidos homogêneos e incompressíveis são uma construção histórica coletiva que se prolongou posteriormente a Pascal, não exatamente são realizações dele ${ }^{12}$ Assim, dependendo da narrativa apresentada, o livro pode fomentar visões individualistas da ciência, bem como trazer referências anacrônicas e distorções do ponto de vista histórico 13

Buscamos verificar se há alguma alusão de cunho histórico-filosófico em trechos dedicados ao Princípio de Pascal nos livros didáticos. Em caso negativo, que impressões essa ausência pode transmitir? Em caso afirmativo, o que é mencionado? O Princípio e sua formulação matemática são atribuídos exclusivamente a Pascal? Há alguma observação sobre a construção histórica do conceito de pressão? A redação do Princípio, se atribuída implícita ou explicitamente a Pascal nos livros, está de acordo com o que o pesquisador afirmou? Que impressões transparecem a esse respeito?

Seria adequado que os livros trouxessem a validade atual do Princípio de Pascal para fluidos em geral, acompanhada da ressalva de que originalmente essa validade, como veremos, foi estabelecida por Blaise Pascal para líquidos, sendo a formulação completa do Princípio resultado de um processo histórico. Dessa forma, seriam contempladas as adequações dos pontos de vista físico, histórico e da natureza da ciência 14

Seria oportuno, ainda, que os obras didáticas pontuassem que o enunciado do Princípio de Pascal encontra-se atualizado também no que diz respeito ao conceito de pressão (além da aplicabilidade a fluidos). Blaise Pascal,

12 Esses elementos decorrentes da pesquisa histórica serão explicitados e explicados oportunamente, à medida que forem apresentados os resultados da análise dos livros didáticos.

13 As referências históricas usualmente observadas em livros didáticos e na divulgação científica deixam transparecer a imagem de que a ciência é fruto de descobertas individuais. A construção coletiva do conhecimento é um aspecto negligenciado. Em artigo relativamente recente, Bagdonas, Zanetic e Gurgel refletem sobre a forma como a "descoberta" da expansão do universo costuma ser apresentada: "é inadequado dizer que 'Hubble descobriu a expansão do universo em 1929'. [...] A criação da teoria do universo em expansão teve vários colaboradores, em um processo que durou alguns anos, envolvendo tanto aspectos teóricos quanto experimentais. [...] na educação básica, em vez de apresentar a expansão do universo como uma descoberta isolada, seria muito mais interessante apresentar a ciência como uma construção coletiva, de forma que não seja tão importante discutir prioridades históricas, sobre quem teria sido o "primeiro" a fazer cada descoberta" 9, p. e2602-11]. A sugestão apresentada pelos autores pode ser estendida a diversos episódios históricos também usualmente citados como "descobertas" isoladas, tais como, a gravidade por Newton, a pressão atmosférica por Torricelli, a radioatividade por Becquerel, dentre muitos outros. Para considerações históricas sobre os referidos episódios, pode-se consultar 39. 41.

14 Como pontuam Peduzzi e Raicik 10 p. 20]: "Um dos objetivos da educação científica na atualidade, em qualquer nível de ensino, é o de promover uma compreensão de natureza da ciência compatível com reflexões filosóficas contemporâneas". A referência ao desenvolvimento histórico do Princípio de Pascal pode colaborar, por exemplo, para a percepção da ciência como um empreendimento coletivo, dinâmico e complexo. ao enunciar a regularidade cujo título o homenagearia, utilizou terminologia no sentido de um "empurrão", remontando a uma compreensão de cunho vetorial de força, e não no sentido de pressão, segundo acepção atual do conceito ${ }^{15}$ Consideramos que poderia ser válido para o professor e para o aluno tomar conhecimento de que, na própria construção do Princípio de Pascal, essa diferenciação do conceito de pressão não foi imediata, nem evidente. É pertinente, para os diferentes atores do contexto educacional, a percepção de que as dificuldades envolvidas no aprendizado do conhecimento físico não são banais, tal como, analogamente, tem sido árduo o caminho de construção do conhecimento na História da Ciência.

Buscamos também analisar como se apresenta nos livros o discurso a respeito de dispositivos tecnológicos relacionados ao Princípio de Pascal. Há coerência com o desenvolvimento histórico tanto do Princípio quanto de tais dispositivos? Que relações entre ciência e tecnologia transparecem nessas passagens dos livros?

Nesse sentido, para além das particularidades históricas, deveria ser observada a atenção a concepções mais complexas sobre as relações entre ciência e tecnologia. Dessa forma, analisamos se os exemplares didáticos, ao abordarem o Princípio de Pascal, reforçam certa visão ingênua de que tecnologia é necessariamente ciência aplicada ${ }^{16}$ Isso porque, em geral, por meio da construção textual realizada, os livros costumam corroborar essa compreensão simplista, não deixando brechas para possibilidades como um caminho inverso, isto é, da tecnologia ao conhecimento científico "17. "as referências mais frequentes à tecnologia incluídas em livros texto

15 Esse aspecto histórico é explicado oportunamente em antecedência aos comentários sobre o que foi notado nos livros didáticos. 16 Como apontam Gil-Pérez e outros autores 43 p. 309]: "Quando perguntamos a professores de ciência 'o que é tecnologia', quase cem por cento das respostas fazem referência a "ciência aplicada'". 17 A trajetória da ciência para a tecnologia não é a única possível. Como destacam Silva e Braga, há uma questão singular que precisa ser trabalhada no contexto educacional: "O ponto de vista sobre a relação ciência-tecnologia que deverá ser superado é o que conceitua a tecnologia como ciência aplicada [...]. Nota-se que grande parte dos alunos concorda que a tecnologia é uma aplicação da ciência 44, p. 7]." Ciência e tecnologia estão estreitamente relacionadas, mas tecnologia não é ciência aplicada. A disponibilidade de tecnologia influencia na direção da pesquisa científica. A investigação científica pode eventualmente levar a aplicações tecnológicas e essas podem aumentar a capacidade de investigação científica. Outros caminhos são notados em episódios da História da Ciência, que não endossam a conceituação da tecnologia como ciência aplicada. No século XVI, as lunetas foram inventadas e, só, posteriormente, desenvolveu-se o conhecimento óptico para explicar o funcionamento desses mecanismos tecnológicos. A elaboração da Termodinâmica ocorreu posteriormente ao surgimento das máquinas térmicas. Explorando particularmente esse episódio histórico, sabe-se que, no século XVII, as necessidades sociais impulsionaram o surgimento e o aperfeiçoamento das máquinas térmicas, baseadas na experiência e no conhecimento empírico de engenheiros, sem que houvesse teorias científicas que explicassem o funcionamento desses artefatos tecnológicos 45. A tecnologia impulsionou o interesse dos pesquisadores, culminando com a elaboração das leis da Termodinâmica: "o desenvolvimento teórico da Termodinâmica surgiu depois das primeiras máquinas a vapor 
são simples enumerações de aplicações do conhecimento científico" [43, p. 309]. Essa perspectiva não é particularmente adequada para alguns dispositivos relacionados ao Princípio de Pascal, como prensas e elevadores hidráulicos. Nos originais de Pascal, o Princípio é enunciado no contexto da explicação desse tipo de mecanismos 18

Autores de livros didáticos deveriam ser cuidadosos ao citarem "aplicações" do Princípio de Pascal e ao atribuírem enunciados modernizados do Princípio a Blaise Pascal. Sem dúvida, esses enunciados atualizados e sua matematização devem ser apresentados no contexto didático, mas com o devido cuidado para não se atribuir a Pascal o que ele não fez. Dependendo da abordagem, o material didático pode incorrer em anacronismos e fomentar visões individualistas sobre a ciência. Ao contrário, mostrar uma construção histórica coletiva do conhecimento é o que prevê a legislação educacional. Em suma, defende-se aqui que a abordagem do Princípio de Pascal deveria contemplar uma História da Ciência bem fundamentada, tendo em vista que esta é:

\section{[...] elemento facilitador para o surgimento de discussões mais profundas sobre a ciência e sua natureza, exatamente por proporcionar aos alunos uma maior reflexão sobre os fenô- menos científicos [46, p. 23]. \\ [...] o foro, onde a análise conceitual pode ser feita; ela permite rever conceitos, criticá-los, recupera significados e os entende à luz de novas descobertas. Ela é, pois, o instrumento da formação intelectual e da assimilação de conceitos. [.. .] a História é o instrumento da formação de uma mente disciplinadamente indisciplinada na crítica dos conceitos cientí- ficos [38, p. 226].}

Mais especificamente, como vem mostrando a literatura, a história da física pode contribuir com o ensino da mecânica dos fluidos [47, 48].

Complementarmente aos elementos históricos, em nossa revisitação aos livros didáticos, não deixamos de lado aspectos físicos conceituais. Abordamos as obras sob o ponto de vista da aplicabilidade do Princípio de Pascal, expressa em seu enunciado e em eventuais exemplos apresentados. Sinaliza-se que o Princípio se aplica a líquidos? Ou ele se aplica a fluidos, englobando também gases, nesse caso? Que especificidades são apontadas?

Esses questionamentos são relevantes na medida em que há frequentes inconsistências do ponto de vista físico no enunciado do Princípio de Pascal em livros didáticos. Atualmente, o referido Princípio se aplica a fluidos, o que inclui líquidos e gases 19

que tiveram uma aplicabilidade funcional. Lembramos que Sadi Carnot editou seu tratado teórico 126 anos depois da patenteada máquina a vapor de Thomas Savery" [44 p. 8].

18 Esse aspecto histórico será retomado mais adiante.

19 A aplicabilidade atual do Princípio de Pascal será demonstrada mais adiante.
Considerando os diferentes âmbitos dos questionamentos expostos, analisamos os 12 (doze) exemplares de livros didáticos de Física aprovados no PNLD 2018. Interessou-nos, particularmente, o primeiro volume dessas coleções, no qual figura o conteúdo relacionado ao Princípio de Pascal. A seguir, apresentamos os resultados obtidos, organizados por temas. Antecendendo os comentários sobre os livros didáticos, e à medida que se fazem necessárias, trazemos para cada tema considerações prévias pertinentes, norteadoras da análise realizada, quer sejam relativas a aspectos do desenvolvimento histórico do Princípio de Pascal, quer sejam considerações analíticas sobre a validade física atual do Princípio 20

\section{Análise dos Livros Didáticos}

\subsection{Autoria do princípio}

Da leitura das fontes históricas emergem percepções sobre o trabalho realizado por Blaise Pascal (1623-1662). O pesquisador francês recorreu a uma terminologia bem elaborada e a uma descrição fenomenológica robusta ao ilustrar situações relacionadas ao que viria a ser chamado "Princípio de Pascal":

[...] um pequeno filamento de água pode manter um grande peso em equilíbrio: resta mostrar qual a razão para essa multiplicação de forças; faremos isso por meio do seguinte experimento. Se um recipiente cheio de água, completamente fechado, tem duas aberturas, uma das quais é cem vezes maior que a outra; colocando em cada uma delas um Pistão que se encaixa exatamente, um homem ao empurrar o Pistão menor irá exercer uma força igual àquela de cem homens empurrando aquele [Pistão] que é cem vezes maior, \& irá superar [a força de] noventa e nove [homens] [31, p. 6].

No seu Traitez de l'Équilibre des Liqueurs (Figura 1), Pascal qualificou explicitamente como um "novo princípio", uma "nova máquina de multiplicar forças", certa regularidade aplicável a líquidos (como o próprio título do livro indicava) e, no caso, mais especificamente à água:

Qualquer que seja a proporção entre as aberturas, se as forças aplicadas aos Pistões

\footnotetext{
20 Os elementos norteadores de caráter histórico e analítico apresentados aqui são similares aos registrados no artigo que publicamos no European Journal of Physics sobre o Princípio de Pascal em livros didáticos do Ensino Superior [30]. Levando em conta possíveis restrições de acesso, optamos por registrá-los no presente trabalho, de modo a garantir o acesso do leitor (incluindo professores da Educação Básica) a elementos balizadores fundamentais também para a análise realizada sobre os livros didáticos aprovados no PNLD 2018.
} 


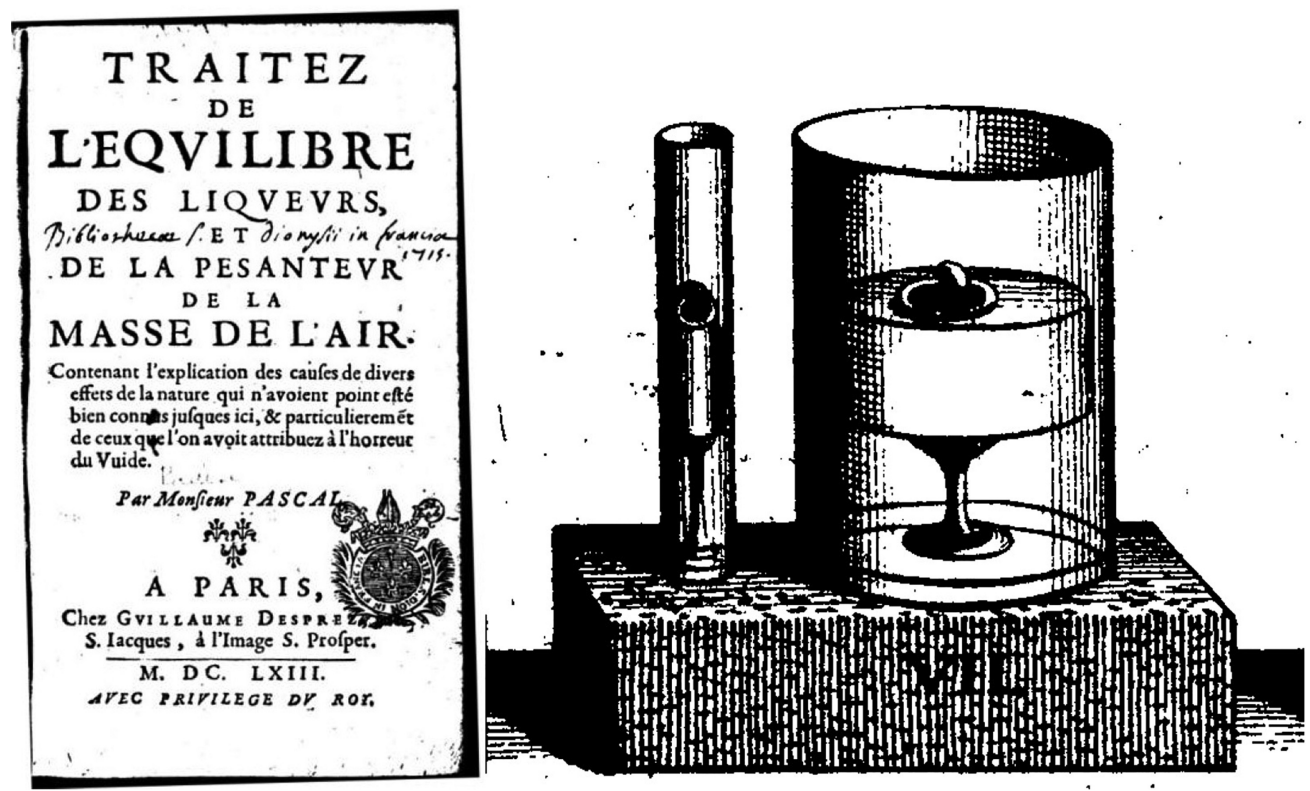

Figura 1: Folha de rosto do Traitez de l'Équilibre des Liqueurs e Máquina de Multiplicar Forças [31 p. 240].

são proporcionais às aberturas, eles estarão em equilíbrio. Então, parece que um Recipiente cheio de água é um novo princípio da Mecânica, e uma nova máquina de multiplicar forças em qualquer grau que desejemos, já que um homem dessa maneira pode elevar qualquer carga que for dada a ele" [31, pp. 6-7, grifos nossos].

Foi assim, então, que Blaise Pascal enunciou o que chamou de "novo Princípio":

[...] está claro que, já que uma dessas aberturas é cem vezes maior que a outra, se o homem que empurra o Pistão pequeno o move para frente uma polegada, ele não irá empurrar o outro mais uma centésima parte de uma polegada, porque, já que esse impulso ocorre por causa da continuidade da água, a qual comunica um dos Pistões ao outro, de modo que um deles não pode se mover sem empurrar o outro, é evidente que, quando o pistão pequeno é movido por [uma distância] de uma polegada, a água que foi empurrada para frente empurra o outro pistão, já que a abertura pela qual ele se move é cem vezes maior, ele não irá ocupar mais do que um centésimo da altura. De modo que o caminho está para o caminho assim como a força para a força; e, essa regra, podemos considerar como a verdadeira causa desse efeito; [...] devem permanecer em Equilíbrio [...] 31, pp. 7-8].

Em livros didáticos, é comum encontrarmos enunciados variados para o Princípio de Pascal. Considerando os referidos elementos históricos, é anacrônica a afirmação de que a aplicabilidade do Princípio a fluidos homogêneos e incompressíveis foi enunciada pelo físico francês Blaise Pascal.

Outros aspectos significativos emergem dos estudos historiográficos. No Traitez de Blaise Pascal, as forças hidrostáticas eram transmitidas por meio de empurrões exercidos pelas porções de água contra porções de água vizinhas ou contra uma superfície:

[...] a água está igualmente pressionada sob esses dois Pistões ${ }^{21}$ porque se um deles tem cem vezes mais peso do que o outro, ele também, por outro lado, toca cem vezes mais partes [de líquido], e então cada parte está igualmente [pressionada]; então todas [as partes] devem estar em repouso, porque não há razão pela qual uma deve ceder mais do que a outra; de modo que se um recipiente cheio de água tem somente uma única abertura, com uma polegada, por exemplo, na qual há um Pistão carregado com uma libra, esse peso exerce um esforço contra todas as partes do recipiente em geral, por causa da continuidade e da fluidez da

\footnotetext{
${ }^{21}$ Em algumas versões em inglês, essa passagem é traduzida como "the water is under equal pressure under the two piston" 35 p. 77, grifos nossos]. Essa tradução não é apropriada, uma vez que o termo "pressure" (pressão), em seu sentido técnico atual, remonta a um escalar, a uma variável de estado. A inclusão do termo "pressão" dá um caráter anacrônico à tradução, a qual em português seria: "a água está sob igual pressão sob esses dois pistões". Transmite-se, assim, a impressão de que Pascal queria dizer mais do que ele de fato disse, como explicaremos mais adiante.
} 
água; mas para determinar o quanto cada parte está sofrendo, aqui está a regra; [...] o peso de uma libra pressiona o Pistão que está na abertura, cada porção do recipiente maior ou do menor sofre precisamente mais ou menos em proporção ao seu tamanho, seja essa porção oposta à abertura, ou lateral, longe ou perto; porque a continuidade e a fluidez da água tornam todas essas coisas iguais e indiferentes [31, pp. 8-9].

Da leitura dessas fontes decorre a percepção de que livros didáticos realizam procedimento de caráter anacrônico, quando imputam a Pascal enunciados atualizados do Princípio, envolvendo conceitos hodiernos de fluido e pressão: "a variação da pressão aplicada a um fluido contido num recipiente fechado é transmitida integralmente a todos os pontos desse fluido" ou, ainda, "o acréscimo de pressão em determinada região de um líquido em equilíbrio é igualmente transmitido a todos os pontos do líquido, inclusive às paredes do recipiente que contém o líquido".

Na citação transcrita anteriormente, não há o termo pressão ou referência ao conceito atual. Ao afirmar que "a água é igualmente pressionada sob os dois Pistões", Pascal utiliza o termo "pressionada" (pressee, no original) no sentido de empurrada. No mesmo sentido, ele se refere a "sofrer um esforço", e menciona, por exemplo, que "esse peso exerce um esforço contra todas as partes do Recipiente em geral" - no original, "ce poids fait effort contre toutes les parties du Vaisseau generalement". Discute uma regra para determinar "quanto cada parte [do recipiente] está sofrendo" - no original, "combien chaque partie souffre" [31, p. 9].

Em que contexto científico esse tipo de noção estava imerso?

O desenvolvimento dos conhecimentos sobre fenômenos da hidrostática envolve diversos personagens desde a Antiguidade: "Arquimedes deu um passo à frente da ciência do peso ao formular os primórdios da hidrostática em seu trabalho sobre corpos flutuantes" [34, p. 2]. Arquimedes (c. 285-212 a.C.) não fez referência a nada similar à nossa ideia atual de pressão, mas sim ao efeito do peso da água contra as paredes de um container [36]. A obra do pensador grego foi o ponto de partida para os trabalhos de Simon Stevin (1548-1620), entre os séculos XVI e XVII: "Ele [Stevin] não deu nenhum relato teórico preciso sobre como as forças são transmitidas de uma parte de um líquido para outra manifestando assim os efeitos hidrostáticos. Vários sucessores que colaboraram a partir de sua hidrostática consideraram esse aspecto problemático" [34, p. 5].

Dentre esses sucessores estavam Isaac Beeckman (1588-1637), René Descartes (1596-1650), Blaise Pascal e Robert Boyle (1627-1691). Blaise Pascal, particularmente, apoiou-se fortemente em argumentos de natureza empírica em seu trabalho, modificando situações propostas anteriormente por Stevin, na sua obra Os elementos da hidrostática, de 1586. Descreveu também experimentos que pode, na prática, não ter realizado 38. Sua preocupação central era explicar como os líquidos transmitiam forças aplicadas a eles.

Entre os historiadores da ciência, é usual a consideração de que, ao pensar a transmissão de forças através do líquido, Blaise Pascal teria, de certo modo, realizado uma introdução, contribuindo, historicamente, para o que viria a ser o conceito de pressão, muito embora sem o uso de um termo equivalente e sem uma compreensão no sentido de uma grandeza escalar [34].

Um elemento de destaque na leitura do texto pascaliano é, portanto, o conceito de pressão. Blaise Pascal e, anteriormente, Simon Stevin usaram termos equivalentes a "empurrar", em sentido que envolvia a noção de forças relacionadas a pesos aplicados contra superfícies, algo como uma grandeza vetorial. Evangelista Torricelli (1608-1647), em seu experimento famoso, comentou sobre a força que evitava o mercúrio descer. Há recorrência nesse tipo de compreensão na época, portanto.

Posteriormente, ao descrever resultados experimentais, Robert Boyle usou o termo pressão para indicar o peso que comprimia o ar. Já no século XVIII, Daniel Bernoulli (1700-1782) passou a usar o termo em referência a uma propriedade de um gás, e não a uma ação externa, mas suas visões a esse respeito não foram bem aceitas na época. A mudança histórica da ideia de pressão como força para uma compreensão moderna de variável de estado ocorreu paulatinamente, como consequência dos avanços tecnológicos da Revolução Industrial 22

22 Para as contribuições de Jean D'Alembert (1717-1783), Daniel Bernoulli (1700-1782), Joseph-Louis Lagrange (1736-1813), Leonhard Euler (1707-1783) e outros pesquisadores, recomendamos [33. Euler dedicou diversos trabalhos à Mecânica dos Fluidos, dentre os quais destacam-se 'Princípios gerais do estado de equilíbrio dos fluidos", "Princípios gerais do movimento dos fluidos" e "Continuação das pesquisas sobre a teoria do movimento dos fluidos". No primeiro deles, Euler expõe pela primeira vez com clareza suas ideias sobre como lidar com o movimento dos fluidos, restringindo-se na ocasião a fluidos não compressíveis. Sobre a conceituação de pressão e sua diferenciação em relação a força, Euler faz contribuições importantes, notadamente se apoiando no contexto científico da época: "[...] define o conceito de pressão como força por unidade de área, embora ainda não com total precisão. Isso não era novidade, já que podia ser notado em d'Alembert, embora ele não tenha explicado isso tão claramente [...]. Em relação a medir a magnitude da pressão, Euler a relaciona com a altura da coluna de água, o que também não é novo. Lembramos que Daniel Bernoulli introduziu um manômetro baseado na altura da coluna de água em seus experimentos, e que Pitot baseou seus experimentos nesses aparatos. Há traços dessa ideia até mesmo em Newton, mas em Euler a ideia de obter o valor de uma medida, e não um equivalente em força, foi uma diferença muito importante. [...] o conceito irá se tornar ainda mais claro nos seus trabalhos seguintes" [33, p. 409]. Da ideia de pressão como a força total agindo em uma superfície ao conceito de força por unidade de área, a construção coletiva do conhecimento se fez presente. A matematização observada nos trabalhos de Lagrange e Euler pode ser compreendida no mesmo sentido, como evidência do caráter colaborativo da atividade científica. 
A construção coletiva dos conhecimentos em hidrostática é examinada detalhadamente em trabalhos historiográficos [33, 34, 36, não sendo nosso objetivo aqui realizar uma narrativa extensa ou aprofundada sobre a História da Mecânica dos Fluidos. Os elementos supracitados já são suficientes para a análise pretendida e contribuem para a percepção de que Blaise Pascal não enunciou o Princípio na forma hodierna. Considerando, assim, os referidos aspectos históricos, o que notamos nos livros didáticos de Física aprovados no PNLD 2018?

Quanto à inserção didática da História da Ciência, muito embora os exemplares analisados componham a totalidade dos aprovados no PNLD 2018, nenhum deles realiza uma abordagem histórico-filosófica para o Princípio de Pascal, seja essa integrada ao conteúdo ou mesmo na forma "add-on", quando o conteúdo científico é apresentado de modo padrão, não-histórico, e uma unidade sobre a História da Ciência é adicionada [42. Nos trechos relativos ao Princípio de Pascal, há total ausência de elementos históricos ou apenas resquícios desses.

Para o conteúdo físico Princípio de Pascal, as referências históricas na obra Física aula por aula são restritas. Indica-se que a unidade de pressão é homenagem a Blaise Pascal, o qual é citado com suas datas de nascimento e morte. O texto didático atribui explicitamente a Pascal conclusões posteriores, alheias ao pesquisador, o que se configura como anacronismo:

Pascal, em 1650, com base em vários experimentos práticos, elaborou o seguinte princípio: Se um ponto qualquer de um líquido homogêneo e incompressível, em equilíbrio, sofre uma variação de pressão $\Delta \mathrm{p}$, todos os pontos desse líquido serão submetidos a essa mesma variação [18, p. 267].

No livro Física para o Ensino Médio, a única referência histórica se restringe à afirmação de que o "fenômeno de transmissão da pressão foi descrito pela primeira vez por Blaise Pascal" 29, p. 275]. No exemplar Física Ciência e Tecnologia, o conteúdo histórico é resumido a uma coletânea de recortes biográficos de pesquisadores destacados ao longo dos capítulos [28. No tocante à Hidrostática, Pascal não é um dos biografados, mas Arquimedes e Stevin são. Não há, ao longo do texto que apresenta o Princípio de Pascal, qualquer referência de cunho histórico à sua construção.

Sem delimitar um enunciado, a obra didática Física, de Bonjorno e colaboradores, apresenta o Princípio de Pascal como uma descoberta, sendo esta referenciada em um único parágrafo com breve alusão histórica:

Por volta de 1650, Blaise Pascal, filósofo, matemático francês (1623-1662) descobriu que qualquer aumento da pressão em um líquido transmite-se igualmente a todos os pontos desse líquido, inclusive às paredes do recipiente que o contém. Essa descoberta ficou conhecida como princípio de Pascal [19, p. 259]; grifos no original].

É possível depreender dessa menção que, em seu trabalho em meados do século XVII, Pascal teria tratado a pressão como escalar, e aplicada às paredes do recipiente. Se há acerto nas supostas considerações históricas, este se restringe a quando os autores consideram que o princípio está relacionado apenas a líquidos na fonte primária - a rigor, água.

O exemplar afirma que "podemos demonstrar a descoberta de Pascal" [19, p. 259] realizando a demonstração matemática por meio da Lei de Stevin. Novamente, notase a ausência de considerações históricas e a priorização de deduções matemáticas.

As referências históricas no Fúsica em Contextos se reduzem à menção de que a unidade de medida da pressão homenageia Pascal e a uma diminuta nota biográfica apresentada lateralmente ao texto: "Blaise Pascal (1623-1662) foi um físico, matemático e filósofo francês que realizou importantes trabalhos na área de Hidrostática e Matemática" [27] p. 189; grifos no original] 23

O enunciado do Princípio de Pascal transparece pelo contexto:

No caso dos vasos comunicantes [...], a pressão é igual para todos os pontos de uma mesma linha horizontal. E, se modificarmos a pressão em qualquer um desses recipientes, essa alteração será transmitida para outro ponto do líquido. Foi Blaise Pascal quem enunciou esse princípio [27, p. 192].

A compreensão atual é, pois, vinculada ao trabalho de Pascal em física - com a pressão como escalar. Assim, na ausência de considerações históricas, pode-se conferir a Pascal a responsabilidade por esse conhecimento no formato hodierno.

O livro Fúsica, de Doca, Biscuola e Villas Bôas, enfatizando a autoria do Princípio, afirma que "a Blaise Pascal devemos o enunciado a seguir": "Um incremento de pressão comunicado a um ponto qualquer de um líquido incompressível em equilíbrio transmite-se integralmente a todos os demais pontos do líquido, bem como às paredes do recipiente" [20, p. 272; grifos no original]. Apresenta, assim, um enunciado como se a pressão, como escalar, e o aspecto da incompressibilidade já fossem elementos explícitos à época no trabalho de Pascal.

A tônica da abordagem realizada pela obra é a matematização, sem referências históricas. Há uma demonstração matemática do Princípio de Pascal a partir

23 Os comentários apresentados ficam circunscritos à forma como o Princípio de Pascal se apresenta na obra Física em Contextos, não sendo outros conteúdos físicos objetos da presente análise. Ressalva-se que a obra trabalha em perspectiva histórica aprofundada conteúdos como a queda dos corpos, os sistemas de mundo heliocêntrico e geocêntrico, a gravitação universal, dentre outros. 
da Lei de Stevin, a lei fundamental da hidrostática para "um líquido homogêneo em equilíbrio sob a ação da gravidade" [20, p. 266]. Na ausência de informações históricas, pode-se ter a impressão de que Pascal, ao estabelecer o Princípio, seguiu esse caminho, realizou os referidos cálculos, e foi responsável pelo conhecimento matematizado apresentado pelo exemplar didático. Pascal, no entanto, não fez demonstração minimamente semelhante no seu Traitez de l'equilibre des liqueurs. Houve sim uma relação entre os trabalhos de Stevin e Pascal, como citamos anteriormente, mas não a que se pode eventualmente depreender a partir desse exemplar didático.

Em um único parágrafo introdutório ao Princípio, a obra didática expõe uma brevíssima síntese biográfica de Blaise Pascal. ${ }^{24}$ Cita datas de nascimento e morte, local de nascimento e áreas de interesse do pesquisador. Refere-se à máquina mecânica de calcular como uma contribuição revolucionária do jovem Pascal, aos 19 anos de idade, após 2 anos de intenso trabalho. O mecanismo permitia a realização de operações aritméticas sem que o usuário precisasse saber os respectivos algoritmos.

O recorte biográfico carece de aspectos humanos e de contextualização. Ao citar a calculadora, por exemplo, o texto deixa passar a oportunidade de contextualizar que a referida contribuição de Pascal foi motivada por fatores familiares, uma vez que o pesquisador auxiliava o pai na tarefa de calcular e cobrar taxas para o governo. O texto comete, ainda, um pequeno equívoco. Afirmase que Pascal nasceu em Clermont-Ferrand. No entanto, Clermont e Ferrand eram separadas em 1623. Corrigimos: Blaise Pascal nasceu na então Clermont, no ano de 1623 (hoje Clermont-Ferrand). De outra sorte, bons aspectos desse recorte são, a nosso ver, os apontamentos de anos de trabalho intenso e do interesse do pensador em outras áreas do saber humano. O pequeno texto se refere a Pascal como cientista ${ }^{25}$ e, igualmente, ressalta a importância de seus trabalhos em Filosofia e Teologia.

A obra didática Ser Protagonista - Fúsica é mais feliz no sentido de evidenciar as relações entre os estudos de Simon Stevin e Blaise Pascal. Demonstra a continuidade dos trabalhos, o que se configura como um apontamento positivo de cooperação na ciência: "Essa conclusão foi apresentada por Blaise Pascal (1623-1662), que aprofundou os estudos desenvolvidos por Simon Stevin" [21, p. 242]. A conclusão em questão se refere à transmissão de pressão através de um líquido, a água.

Essa breve referência histórica se soma ao box "Fatos e Personagens", lateral ao texto didático. Este traz um retrato de Pascal, datas de nascimento e morte,

\footnotetext{
24 O livro realiza o mesmo procedimento em relação a Simon Stevin e outros autores.

25 Há um sutil anacronismo no emprego do termo "cientista" nessa passagem. O referido termo começou a designar os que se dedicavam profissionalmente à ciência apenas a partir do século XIX, após ter sido cunhado, em 1833, pelo estudioso inglês William Whewell (1794-1866). Antes disso, usavam-se as referências "filósofo natural" e "homem da ciência".
}

suas áreas de interesse e apontamentos de aplicações do princípio. No box, o aspecto colaborativo da ciência cede lugar a uma visão individualista: "Blaise Pascal formulou diversos tratados, como a lei do equilíbrio dos líquidos, o triângulo aritmético e o princípio que leva seu nome" [21, p. 242].

A obra Física: Contexto $\&$ Aplicações define que: "Um fluido é uma substância que pode escoar facilmente e que muda de forma sob a ação de pequenas forças. Portanto, o termo fluido inclui os líquidos e os gases" [25] p. 235; grifo no original]. Logo os autores esclarecem que estarão "tratando apenas de fluidos em repouso" [25, p. 235] também quando apresentarem o Princípio de Pascal. Observa-se, no entanto, que na apresentação do enunciado do Princípio não há referência a gases ou menção a fluidos. Afirma-se explicitamente que "essa propriedade dos líquidos é denominada princípio de Pascal" [25. p. 250].

Define-se pressão e, subsequentemente, o Princípio de Pascal é apresentado como aplicação da Lei de Stevin: "Como exemplos de aplicações da equação p = $\mathrm{p}_{\mathrm{atm}}+\rho \mathrm{gh}$, apresentaremos [...] o estudo dos vasos comunicantes e o princípio de Pascal" [25, p. 248]. Há um registro em linguagem matemática do Princípio, seguido do comentário que restringe sua validade a líquidos:

Essa relação foi observada, experimentalmente, em 1653, pelo cientista ${ }^{26}$ francês Pascal, que assim a enunciou: $\mathrm{O}$ acréscimo de pressão, em um ponto de um líquido em equilíbrio, transmite-se integralmente a todos os pontos desse líquido. Por isso, essa propriedade dos líquidos é denominada princípio de Pascal. Observe que, embora na época de Pascal essa propriedade fosse apenas um fato experimental, atualmente verificamos que ela pode ser deduzida imediatamente da equação fundamental da Hidrostática, que, por sua vez, é uma consequência das leis de equilíbrio da Mecânica [25, p. 250].

Essa é a única referência histórica no exemplar no que concerne ao Princípio de Pascal ${ }^{27}$ É pertinente a observação de que a dedução matemática é atual, uma vez que essa nota esclarece relativamente a respeito das origens do Princípio, e desfaz certo anacronismo. O leitor compreende que os cálculos apresentados não foram realizados por Pascal. Por outro lado, permanece a impressão de que este enunciado, nos termos contemporâneos, inclusive no que diz respeito à conceituação

\footnotetext{
26 O uso do termo "cientista" em referência a Pascal constitui um sutil anacronismo (vide nota 24).

27 Nesse exemplar, há outros comentários sobre Pascal no tocante a procedimentos realizados pelo pesquisador em decorrência do experimento de Torricelli: "o cientista e filósofo francês Blaise Pascal (1623-1662) repetiu a experiência no alto de uma montanha e verificou que o valor de patm [pressão atmosférica] era menor do que a pressão ao nível do mar. [...]" [25, p. 242]. Essa afirmação representa uma distorção histórica [40].
} 
para pressão, foi um fato experimental comprovado à época de, e por Pascal.

A obra Ser Protagonista - Física enuncia o Princípio tanto para líquidos quanto para gases, ou seja, para fluidos. A obra didática não afirma que Pascal apresentou o Princípio nesse formato. Contudo, em face da ausência de uma ressalva de cunho histórico, essa pode ser a impressão transmitida ao estudante leitor. O enunciado contemporâneo, com a pressão compreendida como escalar e o fluido (líquido/gás) em estado de repouso, teria sido formulado por Pascal.

Seguindo ao enunciado, a obra Ser Protagonista Física volta a explicar o Princípio com o desenvolvimento de uma relação matemática para a multiplicação de forças. Toma-se, como exemplo, uma situação na qual "duas seringas, de diâmetros diferentes, contêm água e estão interligadas por uma pequena mangueira" 21, p. 242]. O exemplar novamente se exime de considerações históricas, muito embora a alusão à expressão "multiplicação de forças" fosse oportuna para referências nesse sentido, uma vez que remete aos originais de Pascal. Também não há qualquer apontamento histórico a respeito da compreensão de Pascal acerca do conceito de pressão.

Em termos históricos, a obra Conexões com a Física, ao trazer o enunciado do Princípio de Pascal, apenas enumera áreas de interesse do pesquisador, cita sua nacionalidade e datas de nascimento e morte. Pela narrativa construída, tem-se a impressão de que todo o conhecimento sobre o Princípio, inclusive a sua matematização, deveu-se a Pascal:

[Ele] sintetizou essas considerações em um princípio que recebeu seu nome. Princípio de Pascal "Um acréscimo de pressão exercido em um ponto de um líquido em equilíbrio é transmitido integralmente a todos os pontos do líquido e às paredes do recipiente que o contém." Se no ponto 1 ocorrer um acréscimo de pressão $\Delta \mathrm{p}_{1}$, então no ponto 2 acontecerá um aumento de pressão $\Delta \mathrm{p}_{2}$ tal que $\Delta \mathrm{p}_{2}=$ $\Delta \mathrm{p}_{1}$ [26, p. 196].

A referência histórica na obra Física: Interação $e$ Tecnologia se resume a um retrato de Pascal, colocado na lateral do exemplar, com as datas de nascimento e morte do pesquisador. A autoria do Princípio é afirmada explicitamente: "uma das propriedades fundamentais dos fluidos foi enunciada pelo físico francês Blaise Pascal" [23, p. 139], sendo, por isso, a propriedade denominada Princípio de Pascal. O enunciado atual do Princípio é atribuído a Pascal, inclusive como se a pressão já estivesse definida como escalar na primeira metade do século XVII.

Na obra Compreendendo a Física, não há referência à compreensão de Blaise Pascal a respeito do conceito de pressão. A carência de apontamentos históricos pode levar à impressão de que os conhecimentos relacionados ao Princípio, inclusive os cálculos matemáticos, foram elaborados por Pascal. Adicionalmente, pode-se ter a impressão de que coube a Pascal a definição de que o Princípio se aplicava a fluidos. A referência histórica no texto se resume ao apontamento de que a unidade de medida de pressão pascal $(\mathrm{Pa})$ homenageia o "físico, matemático e filósofo francês Blaise Pascal (1623-1662)" [22, p. 254].

$\mathrm{O}$ viés empirista-indutivista é evidenciado no exemplar didático Fúsica, de Guimarães, Piqueira e Carron, o qual considera que o Princípio de Pascal foi um fato observado pelo pensador:

O fato de o acréscimo de pressão ser transmitido a todos os pontos do líquido foi observado por Blaise Pascal (1623-1662), físico e matemático francês. O chamado princípio de Pascal pode ser enunciado da seguinte maneira: $\mathrm{O}$ acréscimo de pressão em determinada região de um líquido em equilíbrio é transmitido a todos os pontos do líquido [24 p. 266].

Os autores aparentam desconhecer a descrição fenomenológica intelectual (não empírica) presente no Traitez de ltequilibre des liqueurs, que - com adaptações e sínteses - é a fonte primária do hodierno Princípio de Pascal.

Na análise das obras didáticas aprovadas no PNLD 2018, encontramos, portanto, exemplares que explicitamente atribuem enunciados atualizados do Princípio ao pesquisador Blaise Pascal. Nesse caso, tem-se uma afirmação equivocada sob o ponto de vista histórico. Não se leva em conta o que Pascal originalmente afirmou. Desconsidera-se a construção coletiva do conhecimento. Fomenta-se, assim, uma concepção anacrônica, do ponto de vista historiográfico, e simplista do tipo individualista, em termos de visões sobre a ciência.

Notamos exemplares, por outro lado, que enunciam o Princípio de Pascal sem qualquer referência explícita à autoria deste. Nada dizem sobre uma suposta autoria individual de Pascal, e nada dizem sobre o fato de que o Princípio adveio de uma construção histórica coletiva, o que incluiria o conceito atual de pressão como grandeza escalar. Nesse caso, temos a ausência de apontamentos históricos. Sendo o Princípio (chamado) de Pascal, a referida lacuna observada nesses exemplares pode também fomentar uma visão de ciência individualista e uma concepção anacrônica, do ponto de vista historiográfico. $\mathrm{Ou}$ seja, tais visões podem ser fomentadas quer se atribua o conhecimento explicitamente a Pascal, quer se omita qualquer explicação sobre a autoria do Princípio que o homenageia.

\subsection{Apresentação do conceito de pressão}

Comentamos anteriormente que, no enunciado inicial estabelecido para o Princípio, Blaise Pascal utilizou termos que remetem a "empurrar", em sentido vetorial, semelhante à noção de força. O desenvolvimento do 
conceito de pressão como uma grandeza escalar ocorreu a posteriori.

Ao apresentarem o enunciado atualizado do Princípio de Pascal, seria relevante que os livros didáticos frizassem explicitamente que a pressão é uma grandeza escalar, uma vez que os estudantes costumam ter dificuldade a respeito dessa grandeza, compreendendo-a de modo similar à força, como vetorial. Essa é, de fato, uma concepção alternativa comum entre os estudantes, o que justificaria tal atenção 34 . O que notamos a esse respeito nos livros didáticos analisados?

Antecedendo a apresentação do Princípio de Pascal, a obra Física: Interação e Tecnologia cita como uma das características dos fluidos:

[...] a capacidade de distribuir uma força exercida sobre eles igualmente para todos os seus pontos. Isso faz com que os pneus de carros [...] e de bicicletas, por exemplo, quando cheios de ar, tenham uma aparência uniforme em toda a sua extensão. Essa particularidade nos permite aplicar o conceito de pressão para os fluidos, uma vez que ele relaciona o valor da força aplicada com a superfície de contato [23, p. 133].

Note-se que o exemplar didático se refere à distribuição de força (não de pressão, o que diverge de uma compreensão contemporânea) e, logo em seguida, a pressão é definida como: "quociente entre o módulo da força aplicada perpendicularmente a uma superfície e a área dessa superfície" [23, p. 133]. O termo "escalar" em referência à pressão não é explicitado. Não se nota preocupação em enfatizar diferenças entre as grandezas pressão e força.

Antes do tratamento sobre pressão em fluidos, Bonjorno e colaboradores recorrem a um exemplo de fixação de dois pregos em uma parede de madeira: um com ponta mais fina do que o outro. É a partir desse exemplo que afirmam pressão, de modo implícito, como escalar: "Matematicamente, definimos a pressão p como o quociente entre a intensidade $\mathrm{F}$ da força aplicada perpendicularmente sobre uma superfície de área $\mathrm{S}$ [...]" [19, p. 247]. Observa-se que essa coleção tem como ênfase exercícios quantitativos.

A obra Conexões com a Fúsica, no início do capítulo "Hidrostática: pressão em fluidos", lança mão de vivências cotidianas para uma contextualização sobre o conceito de pressão. Alude a dores nos ouvidos quando mergulhamos em água, à aferição da pressão sanguínea e à panela de pressão. A partir de outro exemplo pisar com pés descalços na areia -, define pressão média como grandeza escalar, "diretamente proporcional ao módulo da força exercida sobre a superfície de área A e inversamente proporcional à área de contato" [26, p. 184]. Mais exemplos são comentados e, diante disso, em passagem posterior, parece tomar como trivial a compreensão da pressão como escalar no Princípio de
Pascal. Não há uma ênfase explícita na diferenciação entre força e pressão.

A obra didática Física aula por aula, logo antes da referência ao Princípio, no início do capítulo sobre Hidrostática, aborda o conceito de pressão, sem frisá-la como escalar, e sem se preocupar em ressaltar a diferença entre força e pressão. Também ao definir pressão, a obra didática Física - Ciência e Tecnologia não frisa que se trata de uma grandeza escalar, nem enfatiza sua diferença em relação à grandeza força.

No exemplar Ser Protagonista - Física, o termo "escalar" não aparece explicitamente na definição da grandeza pressão como tal: "razão entre a intensidade da força aplicada perpendicularmente a uma superfície e a área dessa superfície" [21, p. 235]. Não há preocupação em enfatizar a diferença entre pressão e força, no sentido de ser uma escalar e a outra vetorial. Também não há qualquer apontamento histórico a respeito da compreensão de Pascal acerca do conceito de pressão.

O Física em Contextos também não se preocupa em ressaltar as diferenças entre as grandezas força e pressão. Não explicita a palavra escalar ao apresentar a grandeza física pressão, trazendo essa adjetivação implicitamente ao afirmá-la como:

[... uma grandeza que depende da força de contato e também da área em que tal força está distribuída. Matematicamente, temos: $\mathrm{p}=\mathrm{F} / \mathrm{A}$ em que $\mathrm{p}$ representa a pressão realizada na superfície de contato, $\mathrm{F}$ a força de contato (ou força normal) e A a área de distribuição da força [27, p. 188].

Em contraste, no livro Física, de Doca, Biscuola e Villas Bôas, no item "Conceito de Pressão", em capítulo sobre Estática dos Fluidos, reforça-se que a pressão é uma grandeza escalar, o que pode contribuir para uma compreensão mais adequada do estudante acerca desse conceito:

A pressão é uma grandeza que não tem orientação privilegiada. Uma evidência disso é o fato de ela ser a mesma, em qualquer direção, em um ponto situado no interior de um fluido em equilíbrio. Por isso, a pressão é uma grandeza escalar, ficando plenamente definida pelo valor numérico acompanhado da respectiva unidade de medida [20, p. 264; grifos no original].

O capítulo "Estática dos fluidos", do livro Fúsica para o Ensino Médio, estabelece primeiramente, antes da apresentação do Princípio de Pascal, uma definição de pressão como escalar: "Pressão é a grandeza escalar cuja intensidade é medida pela razão entre o módulo da força resultante normal [...] e a área [...] da superfície sobre a qual ela atua: $\mathrm{p}=\mathrm{F} / \mathrm{A}[\ldots]$ ". [29, p. 269, grifos no original].

A obra Compreendendo a Física, de Gaspar, ao definir o conceito de pressão, em trecho que antecede o enunci- 
ado do Princípio de Pascal, busca diferenciá-la de força: "Embora força seja uma grandeza vetorial, na definição de pressão se adota o módulo da força normal, por isso pressão é grandeza escalar" [22, p. 254].

Analogamente, na obra didática Física, os autores Guimarães, Piqueira e Carron trazem no capítulo "Fluidos" a ênfase na definição da grandeza pressão como escalar: "Não podemos dizer em que direção age a pressão, mas sim em que direção e sentido vai agir a força aplicada pelo líquido. A pressão se manifesta em todas as direções; é, portanto, uma grandeza escalar" [24, p. 259].

Notamos, assim, que apenas quatro exemplares, dentre os doze analisados, ao apresentarem o Princípio de Pascal ou em antecedência imediata a esse, deram atenção à concepção alternativa comum sobre pressão e se preocuparam em pontuar explicitamente a distinção entre esse conceito e o de força. Contudo, fizeram isso de modo desacompanhado de comentários de cunho histórico. Os demais definiram o conceito de pressão sem a referida ressalva. Em geral, anacronicamente, atribuíram de modo explícito ou implícito o Princípio a Pascal em sua versão atualizada com a pressão como escalar, sem frisar (nessa ocasião) essa característica da grandeza pressão e sem qualquer ressalva específica sobre o desenvolvimento histórico dela.

Parte dos livros analisados parece adotar a perspectiva de que se não há a ressalva de que uma grandeza é vetorial, implicitamente decorre que aquela grandeza é escalar. Consideramos, no entanto, que para o conceito de pressão tal perspectiva não é suficiente, uma vez que os estudantes costumam sustentar concepções alternativas no sentido de que pressão e força são equivalentes. Levando em conta tal particularidade (que pode, sem dúvida, existir para outros casos não objetos da presente investigação), torna-se relevante uma abordagem mais cuidadosa do conceito de pressão.

\section{3. "Aplicações" do Princípio - relações entre ciência e tecnologia}

No que tange a "aplicações" tecnológicas do Princípio de Pascal, algumas particularidades deveriam ser contempladas nas menções realizadas em livros didáticos. Em termos históricos, no que diz respeito a prensas e elevadores hidráulicos, não é propriamente adequado afirmar que o caminho trilhado por Pascal principia no conhecimento científico e culmina na invenção tecnológica. Mais especificamente, a trajetória de Pascal, nesse caso, é peculiar e, poderia ser explorada no ensino do Princípio, colaborando como um contraponto ao que se identifica como "a falta de atenção à tecnologia na educação científica" [43, p. 309].

Conquanto tenha demonstrado explícitas expectativas a respeito da utilidade futura daquele Princípio, Blaise Pascal identificou em seus escritos originais que o mesmo Princípio podia explicar invenções tecnológicas já existentes e bem utilizadas: "E devemos nos admirar que é encontrada nessa Máquina a regra constante que aparece em todas as antigas [Máquinas], tais como o elevador, a roda e o eixo, o parafuso sem fim, etc., ou seja, que o caminho é aumentado na mesma proporção que a força" [31, p. 7]. Como pontuou Chalmers: "Uma vez que ele compreendeu a transmissão hidrostática de empurrões através dos líquidos como uma força por unidade de área, Pascal pôde comparar recursos como a prensa hidráulica a máquinas há muito tempo conhecidas tais como o elevador e a polia" [32, p. 8]. As considerações de Blaise Pascal haviam partido de outros mecanismos de multiplicação de forças já existentes em sua época, e que envolviam sólidos. Era conhecido o mecanismo de multiplicação de forças em máquinas com componentes sólidos, assim como eram conhecidas suas características, a rigidez das alavancas e a extensibilidade limitada das polias. Pascal, então, para explicar os mecanismos envolvendo líquidos, precisou teorizar sobre as propriedades desses, referindo-se à continuidade e fluidez.

O estudo dos trabalhos originais de Blaise Pascal indica que autores de livros didáticos deveriam ser mais cuidadosos ao citarem prensas e elevadores hidráulicos como "aplicações" do Princípio de Pascal, transmitindo uma ideia de desenvolvimento tecnológico posterior, decorrente do conhecimento científico. Transmite-se a impressão de uma trajetória da ciência às invenções tecnológicas: primeiro o estabelecimento do Princípio e, subsequentemente, a invenção de mecanismos e instrumentos nele baseados. Essas narrativas costumam fomentar a visão da tecnologia como ciência aplicada. É importante notarmos, no entanto, que tais mecanismos, especificamente, já eram citados nos originais de Pascal, aparecendo simultaneamente à elaboração do Princípio, sendo este enunciado no contexto da explicação de "uma nova máquina de multiplicar forças em qualquer grau que desejemos, já que um homem dessa maneira pode elevar qualquer carga que for dada a ele" [31, p. 7].

Levando em conta tais considerações, o que podemos observar sobre os exemplares de Física aprovados no PNLD 2018?

Sem ressalvas históricas, o exemplar Fúsica: Contexto 6 Aplicações corrobora a visão de tecnologia como ciência aplicada na subseção "Máquinas hidráulicas": "podem multiplicar forças", ditas uma "importante aplicação" desse princípio [25, p. 250]. O elevador hidráulico é ilustrado e citado como possibilidade de equilibrar uma grande força por meio de outra menor. Elevadores de ônibus acessíveis, cadeiras de dentistas e de barbeiros, e freios hidráulicos são citados como dispositivos que se "baseiam no princípio de Pascal" [25, p. 251].

O exemplar didático Física aula por aula se refere a dispositivos como seringa, prensa hidráulica, elevadores, pontes elevadiças e freios como "aplicações do princípo de Pascal em nosso cotidiano", que têm "a característica de multiplicar a força que é aplicada" [18. p. 267]. Notadamente, a visão de tecnologia como ciência 
aplicada é reforçada. Explica-se sob o viés algébrico o funcionamento da prensa hidráulica e não há referências históricas nessas passagens.

A obra didática Conexões com a Física faz considerações sobre o funcionamento da cadeira de barbeiro, da seringa e do elevador hidráulico, mas não os cita como "aplicações" do Princípio de Pascal. Afirma que Pascal "sintetizou essas considerações" no princípio que o homenageia [26, p. 196]. A narrativa, se mais bem construída, poderia ser afortunada no sentido de se aproximar com propriedade do que historicamente se observa nos originais de Pascal.

Na obra Física: Interação e Tecnologia, apesar do sugestivo título, nota-se que a referência a mecanismos tecnológicos relacionados ao Princípio de Pascal é mínima e desprovida de contextualização histórica. O exemplar afirma apenas que "o funcionamento dos elevadores hidráulicos baseia-se nesse princípio" e acrescenta que "a ampliação de forças é utilizada ainda em prensas, direção e freios hidráulicos" [23, p. 139].

O livro Fúsica, de Doca, Biscuola e Villas Bôas afirma que o Princípio de Pascal "encontra várias aplicações práticas" [20, p. 272]. A alusão denota a contemplação de tecnologias como aplicações do Princípio, isto é, do conhecimento físico. Cita-o como "determinante no funcionamento de alguns dispositivos" [20, p. 272]: o elevador hidráulico de automóveis (prensa hidráulica), o freio hidráulico, os mecanismos hidráulicos em retroescavadeiras e no recolhimento e abaixamento de trens de pouso de aviões. Há um item separado dedicado ao funcionamento da prensa hidráulica, definida como "um dispositivo largamente utilizado cuja finalidade principal é a multiplicação de forças" [20, p. 275]. Registra-se em formulação matemática aquilo que Pascal havia enunciado sobre esse dispositivo, isto é, demonstra-se a multiplicação de forças em termos matemáticos. Contudo, não há qualquer referência histórica nos comentários realizados. Depreende-se que a prensa hidráulica é uma consequência tecnológica moderna do conhecimento científico.

A obra didática Ser Protagonista - Fúsica afirma em box intitulado "Fatos e Personagens", lateral ao texto didático: "O Princípio de Pascal permitiu a invenção de instrumentos e máquinas cujo funcionamento se baseia na transmissão de pressão por meio de líquidos, como o elevador hidráulico e o freio dos veículos automotores" [21, p. 242]. Muito embora este seja um box dedicado a apontamentos históricos, a referida passagem sinaliza uma relação de causa e consequência generalizada, entre o conhecimento científico "Princípio de Pascal" e aparatos tecnológicos, que não condiz com o desenvolvimento histórico da prensa hidráulica, por exemplo. Reforça-se a visão simplista de tecnologia como ciência aplicada. Exteriormente ao box afirma-se, ainda: "Uma das aplicações mais conhecidas dos estudos de Pascal sobre o equilíbrio dos líquidos é o sistema do elevador hidráulico" [21, p. 243]. Melhor seria se no lugar da visão de "aplicação tecnológica" (aparato decorrente do conhecimento físico) estivesse para o elevador hidráulico uma visão relacional, tal como o exemplar expressa acerca de outros aparatos: "cadeiras de dentista e de cabeleleiros também são exemplos de aparelhos que funcionam segundo o mesmo princípio" [21, p. 243].

A obra Compreendendo a Física afirma que o "Princípio de Pascal tem inúmeras aplicações práticas" [22, p. 265]. Examina a prensa hidráulica como exemplo dessas "aplicações práticas", para a qual é desenvolvida uma demonstração matemática. A narrativa, ao apontar uma trajetória do conhecimento científico ao aparato tecnológico, não é exatamente adequada a essa situação. É evidente a visão simplista de tecnologia na qualidade de ciência aplicada transmitida pelo exemplar didático: "o princípio de Pascal é, de fato, um princípio com inúmeras aplicações tecnológicas (como os freios hidráulicos)" [22, p. 266].

O exemplar didático Física - Ciência e Tecnologia destaca que o funcionamento da prensa hidráulica é explicado pelo Princípio de Pascal. Nomeia-a como um "multiplicador de força" e afirma que essa propriedade é utilizada nos elevadores de carros, em centros automotivos. Em box separado, identificado como "Aplicação tecnológica" afirma-se que "um elevador hidráulico nada mais é do que uma prensa hidráulica" [28, p. 162]. Não há qualquer referência à prensa hidráulica do ponto de vista histórico. Assim, tem-se a impressão de que esse tipo de mecanismo não remonta aos trabalhos do próprio Pascal. A referência aos elevadores de carros adiciona a inferência de que se trata de uma aplicação moderna.

No livro Física, de Guimarães, Piqueira e Carron, interessa-nos a conexão inicial que os autores estabelecem entre a multiplicação de forças com uso de fluidos e as máquinas simples: "Vimos no capítulo anterior como multiplicar forças usando máquinas simples, como alavancas, arranjos de polias, etc. Com os fluidos, podemos também obter um arranjo multiplicador de forças" [24, p. 266]. Os autores não fazem alusão à construção histórica do Princípio, muito embora a referência supracitada fosse muito oportuna nesse sentido. Isso porque podemos notar semelhanças entre o caminho delineado nessa apresentação didática realizada no livro e as considerações de Blaise Pascal em seus trabalhos originais: "E é de se admirar que se encontre nessa nova máquina essa ordem constante encontrada em todas as antigas; a saber: a alavanca, a manivela, o parafuso sem fim, etc., que é que o caminho aumenta na mesma proporção que a força" [31, p. 7].

Sobre a prensa hidráulica, a referida obra didática afirma:

[...] se uma das áreas for muito maior do que a outra, a força vai ser multiplicada na mesma proporção. Esse arranjo [...] é utilizado em elevadores hidráulicos [...], para movimentar braços de escavadeiras e em sistemas de freios de veículos em geral [24, p. 266]. 
Os autores não vislumbram a simultaneidade presente nos originais de Blaise Pascal: a descrição fenomenológica e a nova máquina para multiplicar forças foram intelectual e simultaneamente concebidas por ele.

No exemplar Fúsica em Contextos, aparatos tecnológicos são relacionados ao Princípio de Pascal, e não apresentados como aplicação do princípio: "Em nosso cotidiano, o princípio de Pascal está relacionado às prensas e aos elevadores hidráulicos" [27, p. 192]. Convém notar, contudo, que a referência a essas tecnologias "no nosso cotidiano" se somada à ausência de qualquer apontamento sobre indicações de Pascal a respeito desse tipo de mecanismo, pode transmitir a impressão (equivocada) de que são tecnologias caracteristicamente atuais, não cogitadas no passado.

Na obra Física, as primeiras considerações de Bonjorno e colaboradores sobre tecnologias associadas ao princípio de Pascal são pertinentes, pois o assumem como pressuposto teórico que permite adequada compreensão tecnológica: "O princípio de Pascal explica o funcionamento dos elevadores hidráulicos, das seringas de injeção, dos freios hidráulicos dos carros, entre outros" [19, p. 259]. Em outra passagem, logo em seguida, há referência explícita a "aplicações". Afirma-se que: "A prensa hidráulica é uma das aplicações do teorema de Pascal [...] é uma máquina simples que multiplica forças. O uso da prensa hidráulica pode ser observado nos elevadores hidráulicos dos postos de gasolina e também em alguns caminhões basculantes" [19. p. 260]. Os autores parecem desconhecer que a prensa hidráulica foi intelectualmente concebida em paralelo à descrição fenomenológica nos originais pascalinos e terminam por expressar a prensa como exemplo de ciência aplicada. Não há qualquer referência histórica ao fato de que a prensa e os elevadores remontam ao próprio pesquisador. Interessante notar, contudo, que utilizam a expressão "máquina simples que multiplica forças", a qual reporta a Pascal.

Na obra didática Física para o Ensino Médio, a prensa hidráulica é citada em tom de aplicação: "Graças a esse princípio podemos montar um dispositivo multiplicador de força [...]. Tal dispositivo é chamado de prensa hidráulica" [29, p. 276; grifos no original]. Nenhuma referência histórica aparece nessa passagem. A visão de tecnologia como ciência aplicada transparece na narrativa.

Observando a apresentação do Princípio de Pascal nos exemplares analisados, nota-se, portanto, que quase a totalidade deles corrobora a visão de tecnologia na qualidade de ciência aplicada. Essa compreensão é explicitamente reforçada em alguns, dando a impressão de que todos os dispositivos tecnológicos relacionados ao Princípio são aplicações atuais. Nenhum dos livros analisados apontou que Pascal se referiu à elevação de cargas, no contexto dos seus escritos sobre dispostivos para multiplicar forças e ao reconhecer nos mecanismos relacionados à água "um novo Princípio".

\subsection{Aplicabilidade do Princípio}

Podemos esclarecer a que se aplica o Princípio de Pascal, demonstrando sua validade segundo o ponto de vista físico atual 28 Consideraremos as relações entre a Lei de Stevin, a lei das atmosferas e o Princípio de Pascal. A seguinte equação diferencial surge quando se considera um fluido (líquido ou gás), com densidade $\rho$, em equilíbrio:

$$
\frac{d p}{d y}=-\rho g
$$

$y$ é a altitude medida em relação ao nível do mar, $g$ é a aceleração da gravidade e $\rho$ pode depender de vários parâmetros, como pressão e posição. De acordo com a lei das atmosferas, temos o seguinte decaimento exponencial para a pressão, em um ambiente cujo único componente da atmosfera é um gás ideal:

$$
p(y)=p_{0} \exp (-\alpha y), \quad \alpha=\frac{g \rho_{0}}{p_{0}} .
$$

Em (2), y é a altitude considerada em relação ao nível do mar, $g$ é a aceleração da gravidade, $\rho_{0}$ e $p_{0}$ são a densidade e pressão da atmosfera ao nível do mar, respectivamente. Podemos demonstrar que a lei das atmosferas é compatível com a Lei de Stevin, se realizarmos a expansão em série de Taylor da equação (2). Para essa expansão, assumimos implicitamente que a pressão $p_{0}$ ao nível do mar é grande, em comparação com o termo $g \rho_{0}$, e/ou estamos em altitudes $y$ suficientemente baixas:

$$
\begin{aligned}
p(y) & =p_{0} \exp (-\alpha y)=p_{0}\left[1-\alpha y+\frac{1}{2 !} \alpha^{2} y^{2}-\cdots\right] \\
& \simeq p_{0}-\rho_{0} g y
\end{aligned}
$$

(3) é a expressão analítica da lei de Stevin, que aparece em alguns livros didáticos (da Educação Básica ao Ensino Superior) como se fosse declarada pelo próprio Pascal, o que constitui uma inconsistência histórica.

Em algumas literaturas didáticas frequentemente utilizadas na formação superior ${ }^{29}$ na demonstração analítica do Princípio de Pascal, utiliza-se uma expressão que corresponde à equação (3), com referência explícita a um fluido incompressível. E para os gases ideais? Qual seria a expressão analítica para a variação de pressão, isto é, o que ocorre se permitimos uma variação na pressão $p_{0}$ (chamemo-la de $\left.p_{\text {ext }}\right)$ ? Para um gás ideal a uma temperatura constante, a densidade é proporcional

\footnotetext{
28 Evidentemente, não estamos propondo que tal demonstração seja transcrita para um livro didático da Educação Básica. O mesmo comentário se aplica às considerações históricas, se tomadas literalmente. Contudo, no presente trabalho, esta demonstração exerce o papel de justificativa para parâmetros segundo os quais analisamos os livros didáticos, uma vez que dela emerge a aplicabilidade atual do Princípio, tal como esta deveria ser ensinada em qualquer nível.

29 Ver 49, por exemplo.
} 
à pressão, então $\alpha$ deve permanecer constante. De (2), temos que, para um determinado valor constante de $y$ :

$$
\begin{aligned}
p(y) & =p_{\text {ext }} \exp (-\alpha y) \rightarrow \Delta p(y)=\Delta\left[p_{\text {ext }} \exp (-\alpha y)\right] \\
\Delta p(y) & =\Delta p_{\text {ext }} \exp (-\alpha y)
\end{aligned}
$$

Com base nesse resultado, concluímos que os gases ideais não obedecem ao Princípio de Pascal. Para um gás ideal sujeito a uma pressão externa $p_{\text {ext }}$, qualquer variação desta quantidade $\boldsymbol{n} \tilde{\boldsymbol{a}} \boldsymbol{o}$ é transmitida inalterada para outras partes do gás (a menos que $y=0$ ), pois ela depende da posição $y$ onde a pressão é medida.

Há um aparente paradoxo, no entanto, uma vez que sabemos, empiricamente, que os gases podem transmitir uma pressão aplicada, embora não tão rapidamente quanto os líquidos. Há exemplos cotidianos desse comportamento. Quando alguém abre ou fecha a porta de uma sala com cortinas, na janela localizada do outro lado da sala, as cortinas rapidamente se movem. Ou as janelas, ou outra porta na mesma sala, balançam. Por que isso ocorre?

Se comparado às pressões típicas, na prática, o resultado da expressão $g \rho_{0}$ é numericamente pequeno. Além disso, são pequenas as dimensões típicas de sistemas de interesse ao estudar gases. Essas são justamente as condições de validação da equação (3). Assim, em termos atuais, consideramos que os gases também obedecem ao Princípio de Pascal, em uma aproximação de primeira ordem, a temperatura constante, e para pequenas variações da pressão externa (a densidade deles não muda significativamente).

Das considerações precedentes, depreende-se que, do ponto de vista físico atual, o Princípio de Pascal é válido para fluidos, o que compreende, portanto, líquidos e gases. Ao se referirem à validade do Princípio, portanto, os livros didáticos de diferentes níveis deveriam contemplar tal indicação. Quanto a esse aspecto, o que podemos notar na análise dos exemplares de Física aprovados no PNLD 2018?

Em termos conceituais, foram notadas divergências entre os livros didáticos no tocante à aplicabilidade do Princípio de Pascal. Há exemplares que se referem a líquidos, outros especificam líquidos homogêneos e incompressíveis, fluidos líquidos incompressíveis ou fluidos líquidos em equilíbrio. Há exemplares que estendem a validade do Princípio a gases. O Quadro 1 resume os resultados encontrados. Registramos ipsis litteris na primeira coluna à direita em que condições há aplicabilidade do Princípio de Pascal, segundo cada um dos exemplares analisados. É notável a não uniformidade observada nos livros didáticos no registro quanto ao tipo de matéria para o qual o Princípio de Pascal é considerado válido. Há uma (inadequada) multiplicidade de registros.

Na obra didática Conexões com a Física, uma contextualização que remete ao dia-a-dia antecede o enunciado do Princípio e serve para aplicá-lo apenas a fluidos líquidos. Comenta-se sobre a elevação de clientes na cadeira de barbeiro e de carros por dispositivos análogos
Quadro 1: Aplicabilidade do Princípio de Pascal nos exemplares

\begin{tabular}{|c|c|c|}
\hline Título & Autores & $\begin{array}{c}\text { Aplicabilidade } \\
\text { do Princípio } \\
\text { de Pascal }\end{array}$ \\
\hline Física & $\begin{array}{l}\text { Bonjorno } \\
\text { et al. }\end{array}$ & $\begin{array}{l}\text { fluidos líquidos } \\
\text { incompressíveis }\end{array}$ \\
\hline $\begin{array}{l}\text { Física aula } \\
\text { por aula }\end{array}$ & $\begin{array}{l}\text { Barreto Filho } \\
\text { e Silva }\end{array}$ & $\begin{array}{l}\text { líquidos homogêneos } \\
\text { e incompressíveis }\end{array}$ \\
\hline $\begin{array}{l}\text { Conexões com } \\
\text { a Física }\end{array}$ & $\begin{array}{l}\text { Martini, } \\
\text { Spinelli, Reis } \\
\text { e Sant'Anna }\end{array}$ & $\begin{array}{l}\text { fluidos líquidos em } \\
\text { equilíbrio estático }\end{array}$ \\
\hline $\begin{array}{l}\text { Física para o } \\
\text { Ensino } \\
\text { Médio }\end{array}$ & $\begin{array}{l}\text { Yamamoto e } \\
\text { Fuke }\end{array}$ & líquidos em equilíbrio \\
\hline Física & $\begin{array}{l}\text { Doca, } \\
\text { Biscuola e } \\
\text { Villas Bôas }\end{array}$ & $\begin{array}{l}\text { líquidos } \\
\text { incompressíveis em } \\
\text { equilíbrio }\end{array}$ \\
\hline Física & $\begin{array}{l}\text { Guimarães, } \\
\text { Piqueira e } \\
\text { Carron }\end{array}$ & $\begin{array}{l}\text { fluidos líquidos } \\
\text { incompressíveis }\end{array}$ \\
\hline $\begin{array}{l}\text { Física: } \\
\text { Contexto \& } \\
\text { Aplicações }\end{array}$ & $\begin{array}{l}\text { Luz, Álvares } \\
\text { e Guimarães }\end{array}$ & Líquidos \\
\hline $\begin{array}{l}\text { Física em } \\
\text { Contextos }\end{array}$ & $\begin{array}{l}\text { Pietrocola, } \\
\text { Pogibin, } \\
\text { Andrade e } \\
\text { Romero }\end{array}$ & Líquidos \\
\hline $\begin{array}{l}\text { Física: } \\
\text { Interação e } \\
\text { Tecnologia }\end{array}$ & $\begin{array}{l}\text { Gonçalves } \\
\text { Filho e } \\
\text { Toscano }\end{array}$ & Fluidos \\
\hline $\begin{array}{l}\text { Física - } \\
\text { Ciência e } \\
\text { Tecnologia }\end{array}$ & $\begin{array}{l}\text { Torres, } \\
\text { Ferraro, } \\
\text { Soares e } \\
\text { Penteado }\end{array}$ & Fluidos \\
\hline $\begin{array}{l}\text { Compreendendo } \\
\text { a Física }\end{array}$ & Gaspar & Fluidos \\
\hline $\begin{array}{l}\text { Ser Protago- } \\
\text { nista - } \\
\text { Física }\end{array}$ & $\begin{array}{l}\text { Fukui, } \\
\text { Molina e } \\
\text { Venê }\end{array}$ & Fluidos \\
\hline
\end{tabular}
do PNLD 2018.

em oficinas mecânicas: "Nas situações descritas, objetos de grande massa são elevados por meio de uma variação de pressão provocada em um ponto de um líquido" [26. p. 196]. Cita-se também o escoamento de líquido ao ser apertada uma seringa cheia: "Isso acontece porque a pressão exercida sobre a seringa é transmitida aos demais pontos do líquido, provocando seu escoamento pela extremidade aberta" [26, p. 196]. Os autores, pois, restringem o princípio a fluidos líquidos e em equilíbrio (estático, de acordo com o escopo do capítulo específico). Gases não são citados. 
Do ponto de vista físico contemporâneo, porque restrito a fluidos líquidos, o Princípio de Pascal não está atualizado na coleção de Bonjorno e colaboradores [19] $]^{30}$ Em exemplo sobre variação de pressão em tubulação hidráulica de uma residência, outro aspecto de restrição é apresentado: para o Princípio de Pascal ser aplicável ao fluido incompressível, ou de densidade constante, este deve estar em repouso.

Na obra didática, Física aula por aula, a validade do Princípio é indicada somente para líquidos ${ }^{31}$ O exemplar não inclui a validade para gases. Em relação à proposta original de Pascal, nota-se a atualização do Princípio com a referência às características do líquido, "homogêneo e incompreensível".

A obra Conexões com a Física, ao trazer o enunciado do Princípio de Pascal, refere-se exclusivamente a líquidos [26, p. 196]. Já na obra didática Física: Interação e Tecnologia, de Gonçalves Filho e Toscano, afirma-se explicitamente que Pascal enunciou a validade do seguinte Princípio para fluidos: "Se houver uma variação na pressão exercida sobre um fluido contido em um recipiente, ela é integralmente transmitida a todos os pontos do fluido e às paredes do recipiente que o contém" [23, p. 139]. Como se pode notar, há uma atualização nessa afirmação, na medida em que Pascal se referiu apenas a líquidos.

Nota-se no livro Física, de Doca, Biscuola e Villas Bôas, a validade do Princípio de Pascal enunciada para líquidos incompressíveis. Em demonstração, solicita-se que consideremos um cilindro contendo um líquido homogêneo incompressível, sendo a incompressibilidade uma condição lembrada ao longo do processo demonstrativo. Ao final, refere-se ao líquido como "fluido" e não há indicação de que o Princípio se aplique a gases.

Sobre a validade do Princípio, na obra didática Ser Protagonista - Física, alguns comentários são pertinentes. Na introdução do Princípio de Pascal, o exemplar utiliza a representação de "uma garrafa contendo um líquido, com dois orifícios tapados por rolhas" [21, p. 242]. Logo após o exemplo, no entanto, enuncia o Princípio tanto para líquidos quanto para gases, ou seja, para fluidos, cuja definição foi dada anteriormente no livro, sendo caracterizada a diferença entre eles - a incompressibilidade de líquidos e a compressibilidade de gases.

\footnotetext{
30 Pesquisa recente realizada por Schivani e outros autores identificou que a coleção de Bonjorno e colaboradores foi a mais adotada em vinte e um Estados da Federação dentre as obras aprovadas no PNLD 2018 [50]. Como os autores dessa pesquisa apontam, o professor nem sempre é responsável pela escolha do livro adotado na escola. Há situações nas quais o professor solicita uma determinada obra aprovada no PNLD para distribuição em sua escola, mas outra obra é enviada pelo Ministério da Educação. $\mathrm{E}$, quando nenhuma solicitação é realizada, a escola geralmente recebe a obra mais adotada na região.

31 Dentre as obras aprovadas no PNLD 2018, Schivani e outros autores observaram que a segunda coleção mais adotada nas escolas, a Física aula por aula, de Barreto Filho e Silva, foi a preponderante em três Estados da Federação [50].
}

Na obra Compreendendo a Física, a explicação para o Princípio de Pascal se dá a partir da situação de um líquido contido em um recipiente quando um êmbolo é acionado. Já no enunciado apresentado, o Princípio se aplica a fluidos, sendo esses definidos no livro, anteriormente, como líquidos e gases. Em trecho posterior, afirma-se que o Princípio permite "a explicação de muitos fenômenos, como a razão de não sermos esmagados pela pressão atmosférica" [22, p. 266]. E, em um quadro que explica esse fenômeno em destaque, o autor evidencia que o Princípio também é válido para gases: "ar, presente nos pulmões, no estômago e nas orelhas" [22, p. 266].

Na obra didática Física - Ciência e Tecnologia, a explicação do Princípio de Pascal se inicia justamente com um exemplo envolvendo gases. Relata-se a vibração em uma janela devido ao acréscimo de pressão sobre o ar em uma sala e à transmissão desse efeito em todas as direções quando uma porta é batida bruscamente. Ao enunciar o Princípio, o livro se refere à transmissibilidade da "pressão exercida num ponto de um fluido (gás ou líquido)" e destaca, assim, sua aplicabilidade: "vale não apenas para os gases, mas também para os líquidos" [28. p. 160].

Os autores Guimarães, Piqueira e Carron, na obra didática Física, restringem o Princípio de Pascal a fluidos líquidos, incompressíveis. E no Física em Contextos, o exemplo dos vasos comunicantes serve de mote para a apresentação do Princípio de Pascal, cujo enunciado é aplicável a líquidos [27, p. 192]. Não há referência à aplicabilidade do Princípio a gases.

No livro Fúsica para o Ensino Médio, explicitando o estado de repouso de um líquido e tendo implícita a densidade uniforme dele - ou sua incompressibilidade , os autores Yamamoto e Fuke enunciam o Teorema de Stevin. Tal como para esse teorema, o Princípio de Pascal é enunciado com restrição a líquidos:

O fenômeno de transmissão da pressão foi descrito pela primeira vez por Blaise Pascal. O Princípio de Pascal estabelece que: Quando um ponto de um líquido em equilíbrio sofre variação de pressão, acontece o mesmo com os demais pontos dele, em igual intensidade [29, p. 275].

Citam-se como exemplos situações envolvendo líquidos, uma garrafa PET de refrigerante cheia sendo apertada, uma seringa contendo líquido cujo êmbolo é apertado. O enunciado não é estendido a gases.

Dentre os doze exemplares analisados, portanto, quatro estendem a aplicabilidade do Princípio, englobando explicitamente líquidos e gases no enunciado exposto. Os demais apontam a aplicabilidade para líquidos, exclusivamente. Dentre esses, alguns anotam ressalvas quanto às condições dos líquidos, outros não. Não foi notado, em nenhum exemplar, o encaminhamento de trazer a validade atual do Princípio de Pascal para fluidos em geral, acompanhado da ressalva de que originalmente 
Blaise Pascal se referiu apenas a líquidos, sendo a redação completa do Princípio decorrente de um processo histórico.

\section{Sugestões Para Uma Inserção Didática do Princípio de Pascal}

Realizamos uma revisão crítica multicontextual (conceitual e histórica), do Princípio de Pascal nos livros didáticos de Física aprovados no PNLD 2018. Mostramos que há inconsistências nos livros considerados, tanto do ponto de vista conceitual quanto histórico. Há divergências quanto à validade do Princípio de Pascal, havendo tanto referências à validade somente para líquidos quanto para fluidos em geral. A contextualização histórica é minima, se não inexistente. Algumas afirmações atribuem de modo equivocado conhecimentos atualizados (por exemplo, sobre pressão e fluidos) a Blaise Pascal. Transmitem visões individualistas de ciência. A ausência de apontamentos históricos por vezes também causa distorções nesse sentido. Outra dificuldade diz respeito à enumeração de "aplicações" do Princípio de Pascal, que parecem se concretizar todas elas como avanços tecnológicos posteriores ao conhecimento físico. Essa indicação não se mantém em face do escrutínio histórico, o qual não sustenta uma definição estreita de "tecnologia como ciência aplicada".

É conveniente avançarmos no sentido de propormos possíveis soluções a partir desse panorama. Adicionalmente, ressaltamos que, ao consultarmos trechos originais de Blaise Pascal, deparamo-nos com documentos históricos de alto potencial didático que poderiam ser explorados em livros didáticos. Com base nesses dois aspectos, pensamos em elementos que podem, eventualmente, colaborar para uma abordagem mais adequada do Princípio de Pascal nos livros didáticos da Educação Básica, tanto em termos conceituais quanto históricos. Sugerimos uma abordagem históricofilosófica articulada à apresentação do conhecimento físico, contextualizando-o. Esboçamos a seguir um encaminhamento dentre muitos possívei ${ }^{32}$

- Apresentar no livro didático o enunciado atual para o Princípio de Pascal (por exemplo, "a variação da pressão aplicada a um fluido contido em um recipiente fechado é transmitida integralmente a todos os pontos do fluido") e a sua matematização (em nível básico), considerando sua validade para fluidos, tanto líquidos quanto gases. É importante que o livro didático chame a atenção do estudante

\footnotetext{
32 Consideramos que o referido encaminhamento pode, inclusive, inspirar os próprios docentes da Educação Básica em abordagens distintas daquelas contidas nos livros didáticos usuais, uma vez que esses profissionais "têm recusado cada vez mais adotar fielmente os manuais didáticos postos no mercado, na forma como concebidos e disseminados por autores e editoras. Fazem constantemente adaptações das coleções, tentando moldá-las à sua realidade escolar e às suas convicções pedagógicas" 51 p. 147].
}

leitor para a matematização do Princípio, para a sua validade e para a compreensão da pressão como escalar, no enunciado atualizado.

- Expor no livro didático questionamentos para os quais o estudante ainda não tem respostas, com o objetivo de estimular a sua curiosidade: Será que Pascal enunciou o Princípio dessa maneira? O enunciado atual corresponde ao conhecimento inicialmente apresentado por Pascal no século XVII?

- Apresentar ao estudante a transcrição de trechos traduzidos da fonte primária Traitez de l'equilibre des Liqueurs ${ }^{33}$ O objetivo é direcionar o estudante para uma compreensão contextualizada do Princípio de Pascal, que atente para diferenças entre os conhecimentos atuais e do passado ${ }^{34}$ Sugeremse, como possibilidade, os três trechos recortados a seguir:

(I) Se um Recipiente cheio de água, completamente fechado, tem duas aberturas, uma das quais é cem vezes maior que a outra; colocando em cada um delas um Pistão que se encaixa exatamente, um homem ao empurrar o Pistão menor irá exercer uma força igual àquela de cem homens empurrando aquele [Pistão] que é cem vezes maior, \& irá superar [a força de] noventa e nove [homens] [31. p. 6]; (II) Qualquer que seja a proporção entre as aberturas, se as forças aplicadas aos Pistões são proporcionais às aberturas, eles estarão em Equilíbrio. Então, parece que um Recipiente cheio de água é um novo princípio da Mecânica, e uma nova máquina de multiplicar forças em qualquer grau que desejemos, já que um homem dessa maneira pode elevar qualquer carga que for dada a ele. [31, pp. 6-7]; [...] a água está igualmente pressionada sob esses dois Pistões; (III) [...] se um Recipiente cheio de água tem somente uma única abertura, com uma polegada, por exemplo, na qual há um Pistão carregado com uma libra, esse peso exerce um esforço contra todas as partes do Recipiente em geral, por causa da continuidade e da fluidez da água [...]. [31, pp. 8-9].

- A partir da leitura dos referidos trechos, o livro didático pode sugerir que os estudantes, organizados em pequenos grupos, retornem aos

\footnotetext{
${ }^{33}$ Em antecedência a essa etapa, o livro didático pode sugerir que o professor apresente um breve recorte biográfico bem fundamentado sobre Blaise Pascal. Como fonte de consulta para o professor, indicamos trabalho publicado por dois autores do presente artigo [52]. 34 A expressão "compreensão contextualizada" aqui se refere diretamente ao entendimento expresso na BNCC, a qual, como já mencionamos, recomenda em relação à contextualização histórica "a comparação de distintas explicações científicas propostas em diferentes épocas [...] para que os estudantes compreendam a dinâmica da construção do conhecimento científico" [2 p. 550].
} 
questionamentos iniciais, contrapondo os escritos de Blaise Pascal ao enunciado atual do Princípio de Pascal: O enunciado atual corresponde ao conhecimento inicialmente apresentado por Pascal no século XVII? Que semelhanças e diferenças você percebe? Indagações adicionais são recomendadas: O que chama a sua atenção na leitura desses documentos históricos? Qual o foco de Pascal, isto é, o que ele busca descrever? Que termos Pascal usa para se referir ao Princípio? Como ele o explica? A que tipo de matéria se aplicam os comentários do pesquisador? Há referência a fluidos?

- Outras questões mais complexas podem ser sugeridas, as quais demandam uma mediação consistente do professor. Pascal não utiliza o termo pressão, mas se refere a ideias relacionadas: "a água está igualmente pressionada sob os dois Pistões", ele usa o termo "pressionada" (pressee, no original) no sentido de empurrar; "esse peso exerce um esforço contra todas as paredes do Recipiente em geral". O que você percebe sobre a compreensão de Pascal a esse respeito? Parece sinalizar uma grandeza escalar ou vetorial? O que ele sinaliza no século XVII se parece com o conceito de força ou de pressão?

- A redação do livro didático deve explicitar que da reflexão promovida nas etapas anteriores decorre a percepção de que houve uma construção histórica do Princípio, não isolada na figura de Pascal, na medida em que o enunciado atual do Princípio não coincide com os escritos do pesquisador. Sugerese a colocação de um parágrafo explicativo breve sobre o desenvolvimento do conceito de pressão. O livro didático deve esclarecer (tal como destacamos no presente trabalho) que ao explicar como os líquidos transmitiam forças aplicadas a eles, Pascal fez uma introdução ao que historicamente se tornaria o conceito de pressão; houve uma transição desse conceito, de pressão como força, numa compreensão vetorial (notada nos trabalhos de Pascal), até uma compreensão moderna de pressão como variável de estado, no sentido escalar, como consequência de avanços tecnológicos da Revolução Industrial, que impulsionaram a necessidade de medidores para gases. Essa particularidade é um contexto propício para se frisar ao estudante leitor como a tecnologia pode ter impacto importante na ciência. Tendo a situação como exemplo, podese apontar explicitamente a existência de relações complexas de impacto mútuo entre ciência e tecnologia, questionando, assim, uma visão simplificada de que tecnologia é ciência aplicada.

- Finalizando, sugere-se a transcrição (e retomada) do trecho de fonte primária no qual Pascal se refere ao Princípio de Multiplicação de Forças, fazendo um paralelo entre o elevador hidráulico e outros mecanismos já existentes, como a alavanca, por exemplo: "Qualquer que seja a proporção entre as aberturas, se as forças aplicadas aos Pistões são proporcionais às aberturas, eles estarão em Equilíbrio. Então, parece que um Recipiente cheio de água é um novo princípio da Mecânica, e uma nova máquina de multiplicar forças em qualquer grau que desejemos, já que um homem dessa maneira pode elevar qualquer carga que for dada a ele [...]. E devemos nos admirar que é encontrada nessa Máquina a regra constante que aparece em todas as antigas [Máquinas], tais como o elevador, a roda e o eixo, o parafuso sem fim etc., ou seja, que o caminho é aumentado na mesma proporção que a força" [31, pp. 6-7].

- Na transcrição há um movimento que parte da tecnologia para a ciência e volta para a tecnologia. Afasta-se de uma definição simplista de "tecnologia como ciência aplicada". Há uma continuidade entre mecanismos tecnológicos já existentes à época, como alavancas e parafusos sem fim, e ideias e outros mecanismos descritos por Pascal, como a prensa/o elevador hidráulico. O livro didático deve estabelecer uma narrativa consistente com o documento no sentido de apontar explicitamente a complexidade de relações entre ciência e tecnologia, evidenciando a simultaneidade entre a descrição dos novos mecanismos por Pascal e seus estudos sobre a física dos líquidos. O pesquisador ainda demonstrou expectativas em relação à utilidade do Princípio. Mecanismos tecnológicos modernos como o freio hidráulico, dentre outros, explicados com base no Princípio, devem ser citados no material didático.

Diversos caminhos são possíveis para a concretização desse tipo de proposta. Qualquer que seja o formato escolhido pelo autor do livro didático (ou pelo professor que elabora uma intervenção didática), é interessante observar a importância de estimular a reflexão ativa do estudante para uma compreensão detalhada do enunciado atual do Princípio de Pascal e para que considere a possibilidade de uma construção histórica do Princípio, não atrelada exclusivamente a Pascal. Não se sugere uma simples apresentação passiva dos enunciados atual e passado do Princípio. Os estudantes devem ser chamados ao protagonismo na percepção dos contrastes entre esses enunciados, por meio da historicização das fontes primárias, a partir de questões que conduzem a esse objetivo. É importante que o material didático estimule o posicionamento crítico do aluno e dialogue com ele. A inserção didática da História da Ciência, como aqui sugerida, permite, ainda, que os episódios sirvam para a contextualização de discussões relacionadas à Natureza da Ciência, como relações não simplistas entre ciência e tecnologia. E, sem dúvida, para que esse tipo de proposta seja viabilizado, a mediação realizada pelo professor é imprescindível. 


\section{Considerações Finais}

É fundamental a atenção ao conteúdo exposto nos livros didáticos, uma vez que estes exercem um papel importante no ambiente escolar, sendo muitas vezes os únicos recursos de apoio ao professor. Os livros didáticos de Física usualmente trazem poucas referências à História da Ciência. Em alguns casos, textos curtos com conteúdo histórico são deslocados para apêndices ou boxes (com títulos característicos como "Física tem história", "Para saber mais. Sempre foi assim?"). Esse procedimento pode desvalorizar o texto isolado, caracterizando-o como acessório. Quando presente ao longo dos capítulos, a História da Ciência geralmente se resume a quadros ilustrativos e informações, como nomes de pesquisadores considerados mais relevantes, suas datas de nascimento, morte, nacionalidade e descobertas. Considerações que associam o conhecimento científico a seres humanos poderiam contribuir para uma visão de ciência como construção humana. No entanto, esses elementos não parecem ser incluídos em livros didáticos em perspectiva formativa consistente, relacionada à Natureza da Ciência. Sua mera citação não caracteriza a realização de uma abordagem histórica: "não se pode chamar de história da ciência, nos materiais de ensino, simples preâmbulos históricos que, com frequência, orbitando em torno dos resultados da ciência, não escondem a artificialidade inócua de seus fins ilustrativos" [10, p. 32].

Nos livros didáticos aprovados no PNLD 2018, o Princípio de Pascal é enunciado de forma pronta. O enredo da apresentação desse conteúdo parece ter formato essencialmente dogmático: "aprende-se as leis [no caso, o Princípio], as fórmulas que as traduzem e depois sua utilização" 53. Os livros didáticos analisados, em geral, não trazem referências históricas. A ausência de apontamentos históricos leva à impressão equivocada de que Blaise Pascal, sozinho, elaborou o enunciado atual do Princípio (o que engloba o conceito atual de pressão) e realizou os cálculos matemáticos apresentados. Levam a uma percepção distorcida da História da Ciência e fomentam, assim, visões simplistas, individualistas, sobre a Natureza da Ciência.

Nos livros analisados, quando localizada alguma informação histórica, nota-se que a ênfase está na sinalização de que Pascal foi autor de um famoso princípio. Tomando como base a Historiografia da Ciência, podem ser percebidas características de uma História da Ciência Pedigree. Há centralização na busca de precursores do conhecimento científico. Didaticamente, esse estilo contribui para o fortalecimento de visões individualistas da ciência, em contraposição a uma construção coletiva. Os textos não indicam uma construção histórica coletiva do Princípio em questão. Pelo contrário, sugerem que toda a elaboração, e a referência atualizada à ideia de pressão, deveu-se a Pascal (inclusive o leitor pode estender essa visão, por inferência, à formulação matemática mostrada), o que se configura como um anticronismo.
Tem-se a impressão de que, na época de Pascal, o conceito de pressão estava bem estabelecido em termos atuais.

As breves referências históricas notadas em alguns exemplares não fazem jus ao desenvolvimento histórico do Princípio de Pascal. Nesse caso, particularmente, não cumprem o papel didático que caberia à História da Ciência de acordo com a legislação educacional, os editais do PNLD e as indicações acadêmicas especializadas.

Ao citarem eventuais mecanismos tecnológicos relacionados ao Princípio de Pascal, em geral, os livros didáticos os sinalizam como "aplicações" do Princípio, o que não condiz propriamente com os episódios históricos envolvidos no caso de alguns mecanismos citados. Além disso, pela narrativa observada nos materiais didáticos analisados, há uma forte tendência ao reforço da visão simplista de tecnologia como ciência aplicada. Não se aproveitam oportunidades para, de modo contextualizado, explorar o papel da tecnologia na educação científica.

Em termos físicos, nos exemplares analisados, notase, em antecedência à apresentação do Princípio de Pascal, a preocupação de definir o conceito de fluido. As definições são, em geral, imediatas: fluido é aquilo que flui. A definição de fluido e a caracterização de diferenças e semelhanças entre líquidos e gases avançam, nos materiais didáticos analisados, rumo à enunciação do Princípio de Pascal. Não obstante a definição de fluido contemplar gases, é comum que o texto sobre o Princípio de Pascal se refira a líquidos e não mencione gases. E, dessa forma, segundo dois terços dos exemplares, o Princípio não se aplica a gases, mas sim apenas a líquidos. Essa definição está em desacordo com o ponto de vista físico atual. Notam-se, em suma, divergências entre os livros didáticos da Educação Básica analisados. Em menor número estão os que sinalizam a aplicabilidade do Princípio a fluidos.

Em publicação recente, analisamos também os livros didáticos em inglês mais utilizados na formação de docentes, bacharéis em Física e engenheiros em universidades no exterior 35 dos quais sabemos que são traduções as edições brasileiras, geralmente utilizadas na formação desses profissionais no Brasil [30. O panorama encontrado foi muito semelhante:

35 Foram analisados os seguintes exemplares: W. J. Halliday, R. Resnick, Fundamentals of Physics (New York, Wiley, 2014); P. A. Tipler, G. Mosca, Physics for Scientists and Engineers (San Francisco, Freeman, 2007); R. A. Serway, J. W. Jewett, Physics for Scientists and Engineers (Boston, Cengage Learning, 2013); H. D. Young, H D, R. A. Freedman, University Physics (With Modern Physics) (London, Pearson Education, 2016); J. D. Cutnell, K. W. Johnson, Physics (New York, Wiley, 2012); P. G. Hewitt, Conceptual Physics (London, Pearson Education, 2014); R. D. Knight, Physics for Scientists and Engineers: A Strategic Approach with Modern Physics (London, Pearson Education, 2016); H. C. Ohanian, J. T. Markert, Physics for Engineers and Scientists (New York, W.W. Norton \& Company Ltd, 2017); D. C. Giancoli, Physics for Scientists $\&$ Engineers with Modern Physics (London, Pearson Education, 2008). 
Ao abordarem o conteúdo físico "Princípio de Pascal", os livros-texto analisados, em geral, não trazem referências históricas. [...]. Eles levam a uma percepção distorcida da História da Ciência e transmitem visões simplistas e individualistas sobre a ciência. Quando citam eventuais mecanismos tecnológicos relacionados ao Princípio de Pascal, em geral, os livros textos os sinalizam como "aplicações" do Princípio, o que não é precisamente consistente com os episódios históricos envolvidos no caso de alguns dos mecanismos mencionados. Além disso, devido à narrativa observada nos livros-texto considerados, há uma forte tendência a reforçar a visão simplista de tecnologia como ciência aplicada [...]. A respeito da aplicabilidade do Princípio de Pascal, encontramos diversas discrepâncias [...]. A variação no tipo de matéria para as quais o Princípio de Pascal é considerado válido, encontrada nas fontes analisadas, resulta em confusão especialmente para o estudante da graduação que recorre a bibliografias distintas [30, pp. 19-20].

Os livros didáticos do ensino superior, utilizados na formação dos licenciados em Física (os quais, por sua vez, utilizarão os livros didáticos aprovados no PNLD) apresentam divergências entre si quanto à aplicabilidade do Princípio (tal qual se nota nos livros didáticos da Educação Básica): alguns se referem a líquidos, outros a fluidos, o que englobaria tanto líquidos quanto gases. Os docentes da Educação Básica, em sua formação, têm sido expostos a materiais didáticos que trazem o Princípio de Pascal de forma historicamente descontextualizada, carregada de visões simplistas sobre a ciência e sobre as relações entre ciência e tecnologia, contendo imprecisões conceituais. A depender desse aspecto formativo, os docentes não teriam subsídios para uma visão mais crítica em relação ao contéudo sobre o Princípio de Pascal apresentado pelos livros didáticos no PNLD 2018. Pelo menos a julgarmos pelos livros didáticos utilizados na formação docente, diríamos que esses indivíduos teriam dificuldade para realizarem abordagens do Princípio de Pascal distintas daquelas observadas na maior parte dos livros didáticos que utilizam em sala de aula.

Consideramos que a análise pode contribuir produtivamente, por não ser uma consideração geral sobre inadequações presentes nos livros. Buscamos avançar, sinalizando que algumas distorções ou fragilidades presentes nesses materiais podem ser eventualmente corrigidas à luz dos apontamentos realizados, colaborando para a introdução de aspectos histórico-filosóficos na abordagem do referido conteúdo físico.

\section{Agradecimentos}

Agradecemos à Bibliothèque Nationale de France (https://gallica.bnf.fr) pela autorização para reprodução dos originais de Blaise Pascal.

\section{Referências}

[1] MEC - Ministério da Educação, Parâmetros Curriculares Nacionais (Ensino Médio): Ciências da Natureza, Matemática e suas Tecnologias (MEC/SEMTEC, Brasília, 2000).

[2] MEC - Ministério da Educação, Base Nacional Comum Curricular (MEC/SEMTEC, Brasília, 2018).

[3] L.M.C. Nardi e C.C. Silva, Revista Brasileira de Ensino de Física 43, e20200396 (2021).

[4] MEC - Ministério da Educação, Edital de convocação para o processo de inscrição e avaliação de obras didáticas para o Programa Nacional do Livro Didático (PNLD 2018) (MEC/CGPLI, Brasília, 2015).

[5] I. Gurgel, Caderno Brasileiro de Ensino de Física 37, 333 (2020).

[6] D. Ortega e B.A. Moura, Revista Brasileira de Ensino de Física 42, e20190114 (2020).

[7] R.A. Martins, em: Estudos de história e filosofia das ciências: subsídios para aplicação no ensino, editado por C.C. Silva (Livraria da Física, São Paulo, 2006).

[8] A. Guerra, em: Controvérsias na Pesquisa em Ensino de Física, editado por S. Camargo, L.G. Genovese, J.M.H.F. Drummond, G.R. Queiroz, Y. Nicot, S.S. Nascimento (Livraria da Física, São Paulo, 2014).

[9] A. Bagdonas, J. Zanetic e I. Gurgel, Revista Brasileira de Ensino de Física 39, e2602 (2017).

[10] L.O.Q. Peduzzi e A.C. Raicik, Investigações em Ensino de Ciências 25, 19 (2020).

[11] D. Gil-Pérez, I.F. Montoro, J.M. Alís, A. Cachapuz e J. Praia, Ciência \& Educação 7, 125 (2001).

[12] A. Vilas Boas, M.R. Silva, M.M. Passos e S.M. Arruda, Caderno Brasileiro de Ensino de Física 30, 287 (2013).

[13] J.A. Acevedo-Díaz, A. García-Carmona e M.M. Aragón, Educación Química 28, 181 (2017).

[14] H. Kragh, An introduction to the historiography of science (Cambridge University Press, Cambridge, 1987).

[15] C.R. Pagliarini, Uma Análise da História e Filosofia da Ciência Presente em Livros Didáticos de Física para o Ensino Médio. Dissertação de Mestrado, Universidade de São Paulo, São Paulo (2007).

[16] R.P. Batista, A. Mohr e N. Ferrari, em: Anais do VI Encontro Nacional de Pesquisa em Educação em Ciências (Florianópolis, 2007).

[17] P.H.O. Vidal e P.A. Porto, Ciência \& Educação 18, 291 (2012).

[18] B. Barreto Filho e C.X. Silva, Física aula por aula (FTD, São Paulo, 2016), v. 1.

[19] J.R. Bonjorno, C.M. Ramos, E.P. Prado, V. Bonjorno, M.A. Bonjorno, R. Casemiro e R.F.S.A. Bonjorno, Física (FTD, São Paulo, 2016), v. 1.

[20] R.H. Doca, G.J. Biscuola e N. Villas Bôas, Física (Saraiva, São Paulo, 2016), v. 1. 
[21] A.B.M. Válio, A. Fukui, B. Ferdinian, G. Alvarenga de Oliveira, M.M. Molina e V. Santiago de Oliveira, Ser protagonista: física (Edições SM, São Paulo, 2016), v. 1.

[22] A. Gaspar, Compreendendo a física (Ática, São Paulo, 2016), v. 1

[23] A. Gonçalves Filho e C. Toscano, Física: interação e tecnologia (Leya, São Paulo, 2016), v. 1.

[24] O. Guimarães, J.R. Piqueira e W. Carron, Física (Ática, São Paulo, 2016), v. 1.

[25] A.M.R. Luz, B.A. Álvares, C.C. Guimarães, Física: contexto $\mathscr{G}$ aplicações (Scipione, São Paulo, 2016), v. 1.

[26] G. Martini, W. Spinelli, H.C. Reis e B. Sant'Anna Conexões com a física (Moderna, São Paulo, 2016), v. 1.

[27] M. Pietrocola, A. Pogibin, R. Andrade e T.R. Romero, Física em contextos (Editora do Brasil, São Paulo, 2016), v. 1.

[28] C.M.A. Torres, N.G. Ferraro, P.A.T. Soares e P.C.M. Penteado, Física: ciência e tecnologia (Moderna, São Paulo, 2016), v. 1.

[29] K. Yamamoto e L.F. Fuke, Física para o ensino médio (Saraiva, São Paulo, 2016), v. 1.

[30] D.H.A.L. Anselmo, J.M. Hidalgo e D.M. Queiroz, European Journal of Physics 41, 063001 (2020).

[31] B. Pascal, Traitez de ltequilibre des liqueurs, de la pesanteur de la masse de l'air, contenant l'explication des causes de divers effets de la nature qui n'avoient point esté bien connus jusques ici, 6 particulierement de ceux que l'on voit attribuez à l'horreur du vuide (Chez Guillaume Desprez, Paris, 1663).

[32] A. Chalmers, Studies in History and Philosophy of Science 51, 1 (2015).

[33] J.S. Calero, The Genesis of Fluid Mechanics 1640-1780 (Springer, Dordrecht, 2008).

[34] C. Frontali, Physics Education 48, 484 (2013).

[35] W.F. Magie, A source book in physics (Harvard University Press, Cambridge, 1969).

[36] R.A. Martins, Cadernos de História e Filosofia da Ciência 1, 3 (1989).

[37] L.O.Q. Peduzzi, Evolução dos Conceitos da Física (UFSC/EAD/CED/CFM, Florianópolis, 2011).

[38] P.M.C. Dias, Revista Brasileira de Ensino de Física 23, 226 (2001).

[39] R.A. Martins, em: Estudos de História e Filosofia das Ciências, editado por C.C. Silva (Livraria da Física, São Paulo, 2006).

[40] J.M. Hidalgo, J.M. Alves, F.A. Souza e D.M. Queiroz, Alexandria: Revista de Educação em Ciência e Tecnologia 11, 101 (2018).

[41] R.A. Martins, Caderno Catarinense de Ensino de Física 7, 27 (1990)

[42] M.R. Matthews, Science teaching: the role of history and philosophy of science (Routledge, New York, 1994).

[43] D. Gil-Pérez, A. Vilches, I. Fernández, A. Capachuz, J. Praia, P. Valdés e J. Salinas, Science \& Education 14, 309 (2005).

[44] M. O. Silva, M.A.B. Braga, em Anais do VIII Encontro Nacional de Pesquisa em Educação em Ciências, editado por I. Martins, M. Giordan (ABRAPEC, Campinas, 2011).
[45] G.R. da Silva e N.C.G. Errobidart, História da Ciência e Ensino: construindo interfaces 19, 71 (2019).

[46] B.C. Araújo, História da ciência como estratégia didática no ensino médio: um breve olhar de conteúdos da óptica. Dissertação de Mestrado, Universidade Federal do Rio Grande do Norte, Rio Grande do Norte (2013).

[47] L.D. Oliveira, A história da física como elemento facilitador na aprendizagem da mecânica dos fluidos. Dissertação de mestrado, Universidade Federal do Rio Grande do Sul, Rio Grande do Sul (2009).

[48] F.L. Silveira e A. Medeiros, Caderno Catarinense de Ensino de Física 26, 273 (2009).

[49] J. Walker, D. Halliday e R. Resnick, Fundamentals of physics (Wiley, New York, 2014).

[50] M.T. Schivani, G.F. Souza e N. Lira, Revista Brasileira de Ensino de Física 42, e20200011 (2020).

[51] J. Megid Neto e H. Fracalanza, Ciência \& Educação 9, 147 (2003).

[52] D.M. Queiroz e J. M. Hidalgo, Caderno Brasileiro de Ensino de Física 36, 457 (2019).

[53] P. Langevin, em Ciência e Técnica: antologia de textos históricos, editado por R. Gama (T. A. Queiroz, São Paulo, 1992) 